\title{
WestVirginiaUniversity
}

THE RESEARCH REPOSITORY @ WVU

Graduate Theses, Dissertations, and Problem Reports

2010

\section{Predicting the gas-condensate extended composition analysis}

Muzher I. Almusabeh

West Virginia University

Follow this and additional works at: https://researchrepository.wvu.edu/etd

\section{Recommended Citation}

Almusabeh, Muzher I., "Predicting the gas-condensate extended composition analysis" (2010). Graduate Theses, Dissertations, and Problem Reports. 2089.

https://researchrepository.wvu.edu/etd/2089

This Thesis is protected by copyright and/or related rights. It has been brought to you by the The Research Repository @ WVU with permission from the rights-holder(s). You are free to use this Thesis in any way that is permitted by the copyright and related rights legislation that applies to your use. For other uses you must obtain permission from the rights-holder(s) directly, unless additional rights are indicated by a Creative Commons license in the record and/ or on the work itself. This Thesis has been accepted for inclusion in WVU Graduate Theses, Dissertations, and Problem Reports collection by an authorized administrator of The Research Repository @ WVU. For more information, please contact researchrepository@mail.wvu.edu. 


\title{
PREDICTING THE GAS-CONDENSATE EXTENDED COMPOSITION ANALYSIS
}

Muzher I. Almusabeh

Thesis Submitted to

College of Engineering and Mineral Resources

At West Virginia University

In partial fulfillment of the requirements for the degree of

\author{
Master of Science \\ In \\ Petroleum and Natural Gas Engineering
}

Dr. Khashayar Aminian, PhD., Chair

Samuel Ameri, M.S.

Dr. Yuemin Cheng, Assistant Professor.

Department of Petroleum and Natural Gas Engineering

Morgantown, West Virginia

Keywords: phase behavior prediction, heptanes plus components, equations of state, compositional analysis 


\section{ABSTRACT \\ PREDICTING THE GAS-CONDENSATE EXTENDED COMPOSITION ANALYSIS}

\section{Muzher I. Almusabeh}

The objective of this study was to predict the extended composition of gas condensate fluid in order to enhance phase behavior prediction via equation of state. This research work introduces a systematic methodology to estimate the extended heptane plus composition by matching the mole fraction, the average molecular weight, the average specific gravity and the dew point pressure. For the extended method to be accepted, the averaging properties results should be within $3 \%$ of the lab results. A number of published compositional data have been used to verify the reliability of this methodology. Four different methods are compared and analyzed, and the methods that best suit for characterization of heptane plus are discussed.

Characterization of heptane plus prediction involves determining average molecular weight, specific gravity and the dew point pressure. The first two properties are calculated. The dew point is derived from a PC version of PR-AGA software which utilizes Peng-Robison equation of state. The results using all methods are compared and discussed. 


\section{ACKNOWLEDGEMENTS}

I take this opportunity to express my thanks and gratitude to Dr. Khashayar Aminian, academic advisor for my Masters program who has also been a constant source of support and encouragement for me. I am appreciative to have worked under his expert, guidance and friendly demeanor.

I express my sincere appreciation and gratefulness to Prof. Samuel Ameri for his continuous guidance in every aspect of my Masters study and for his advice in matters beyond and above my studies. It is my pleasure and honor to have him on my committee.

I express my gratefulness and gratitude to Dr. Yuemin Cheng for her patient tutelage and her excellent guidance in my research and thesis. I also thank her for considering my request for being on my committee. Her presence on my committee is highly appreciated.

I would like to thank everyone in the Department of Petroleum and Natural Gas Engineering, especially Ms. Beverly Matheny for her friendly ambience.

I would like to express especial thanks from my heart to Mr. Salam P. Salamy, Unplaced division level of E\&P continuing excellence Department for his helps and advices in every aspect in my life especially my career and my education.

Finally, I would like to thank and dedicate this thesis to my family, my relatives and my friends who pray for me and encourage me during my studying the master degree at West Virginia University, a very memorable one. 


\section{TABLE OF CONTENTS}

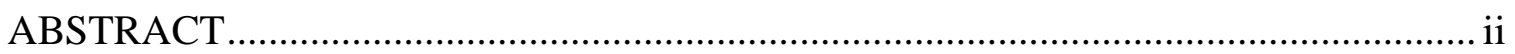

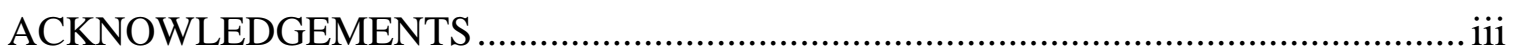

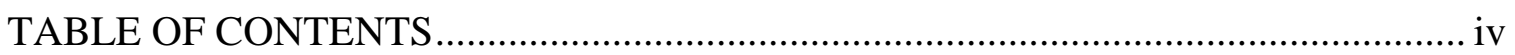

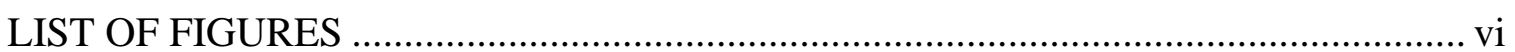

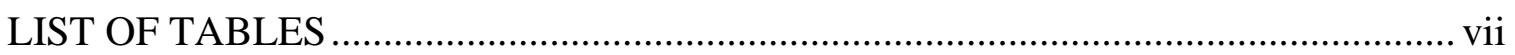

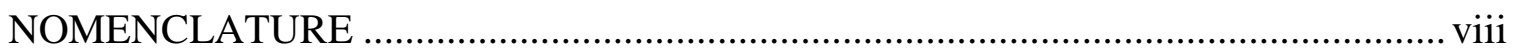

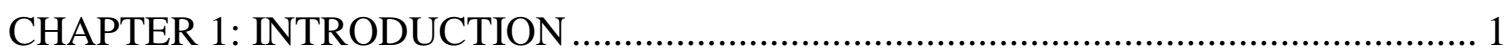

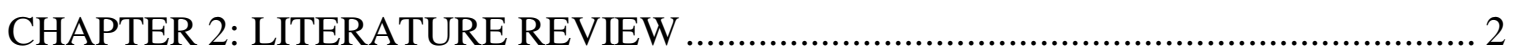

2.1 Retrograde Gas Condensate Reservoir Behavior................................................... 2

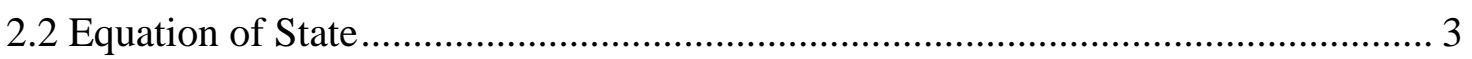

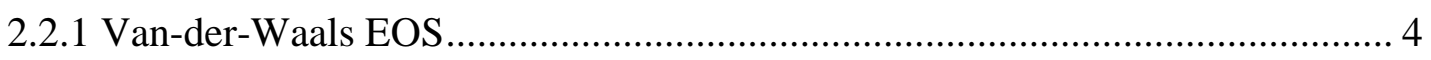

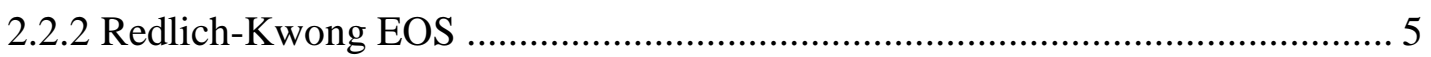

2.2.3 Soave-Redlich-Kwong EOS ................................................................. 5

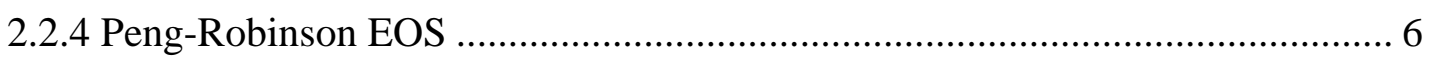

2.3 Predicting the Phase Behavior of Hydrocarbon Systems Using P-R EOS ................ 6

2.3.1 The Input File for the PR-AGA Phase Behavior Package ................................. 7

2.3.2 The Output File for the PR-AGA Phase Behavior Package .............................. 9

2.4 Extended Compositional Analysis Methods ……………………........................ 10

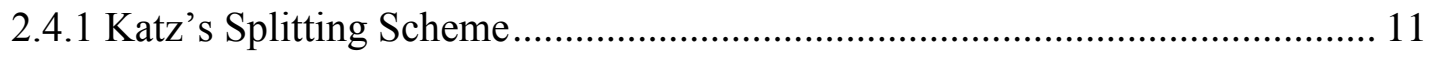

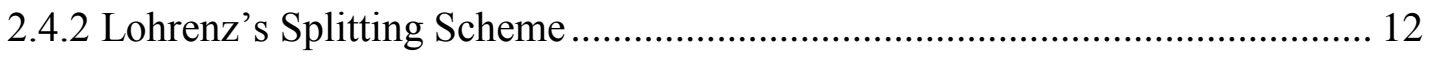

2.4.3 Pedersen's Splitting Scheme.................................................................... 12

2.4.4 Ahmed's Extend Method ....................................................................... 12

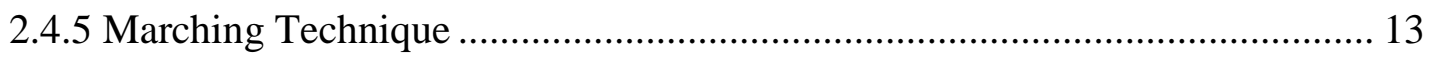

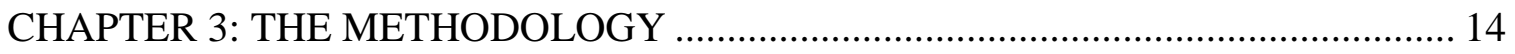

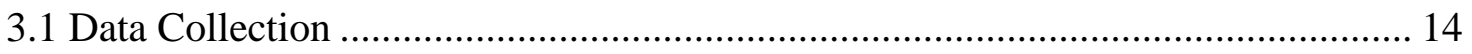

3.1.1 Pazanan Gas Condensate Field, Iran ......................................................... 14

3.1.2 Rapid River 35 Gas Condensate Field, Michigan, USA .................................. 15

3.1.3 Cold Spring 12 Gas Condensate Field, Michigan, USA .................................. 16

3.1.4 Chester 15 Gas Condensate Field, Michigan, USA ........................................ 16

3.1.5 Khuff 4 Gas Condensate Field, Qatar .......................................................... 17

3.1.6 Dakhni Gas Condensate Field, Pakistan ...................................................... 18

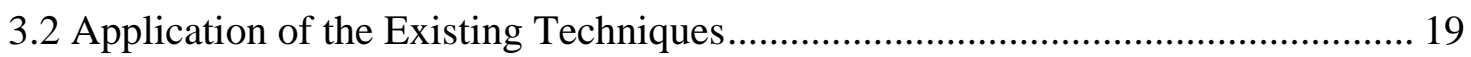


3.2.1 Application of Splitting Schemes to Pazanan Field Data .......................... 20

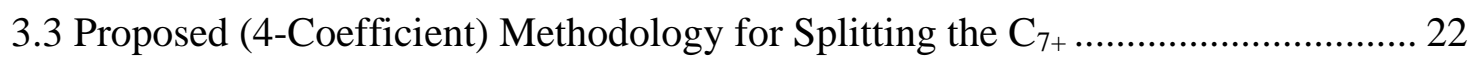

3.3.1 Splitting Sample of Pazanan Field by 4-Coefficient Method .......................... 24

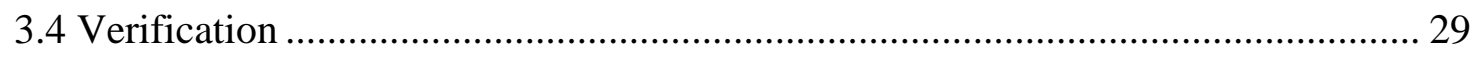

3.4.1 Rapid River 35 Field ......................................................................... 29

3.4.2 Cold spring 12 Field............................................................................. 30

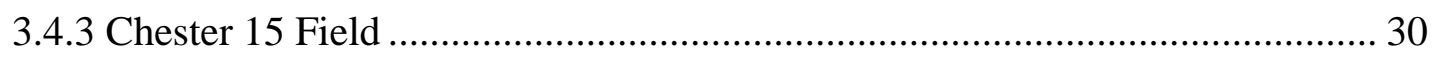

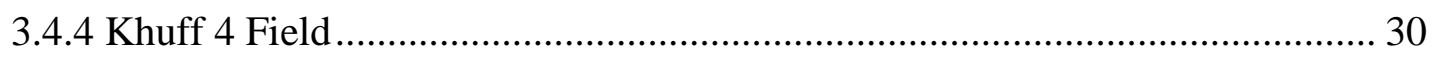

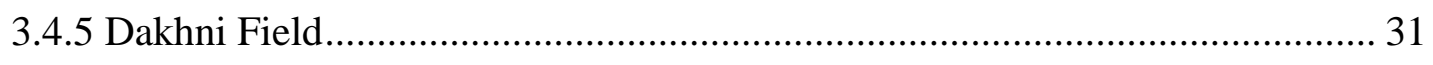

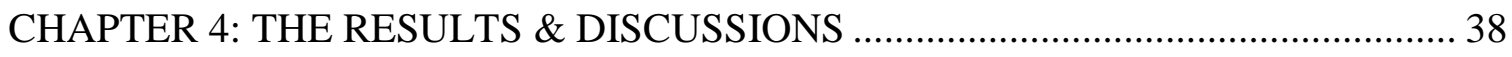

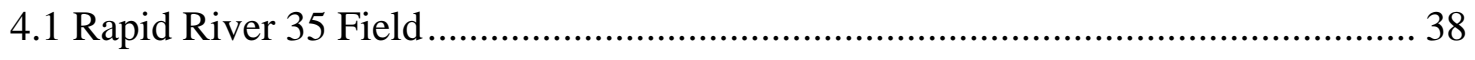

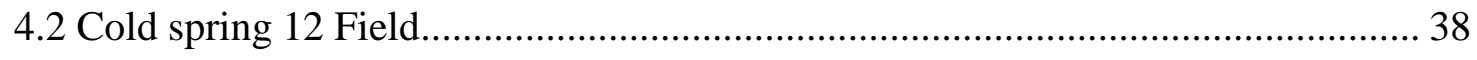

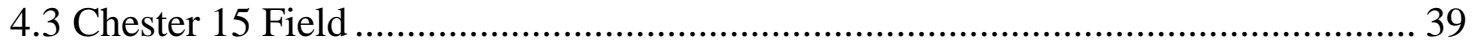

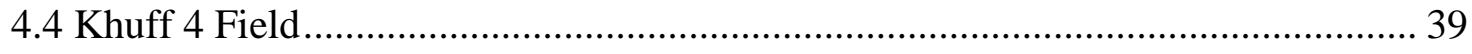

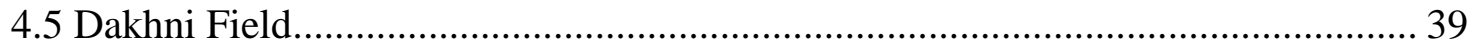

CHAPTER 5: CONCLUSIONS \& RECOMMENDATIONS .......................................... 48

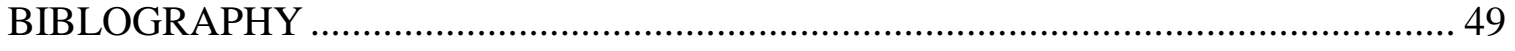

APPENDIX: GENERALIZED PHYSICAL PROPERTIES ………………………......... 52 


\section{LIST OF FIGURES}

Figure 1: The Pressure-Temperature (P-T) Phase Diagram. .......................................... 2

Figure 2: The Typical Input File of the PR-AGA Phase Behavior................................. 8

Figure 3: Typical Input File with Critical Properties and Interaction Coeffcients. ............ 8

Figure 4: The Typical Output File of the PR-AGA Phase Behavior. .............................. 9

Figure 5: Comparison of various Splitting Scheme results for Pazanan Field Data........ 22

Figure 6: The compositional analysis for the sample with 30 and 26 component........... 28

Figure 7: Comparison of Various Splitting Scheme Results with the 4-Coefficient Result

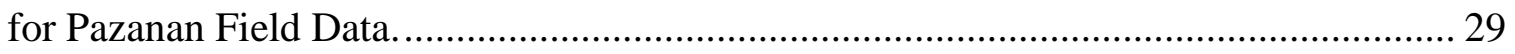

Figure 8: Comparison of the Heptane plus in Gas Phase.............................................. 32

Figure 9: Comparison of the Well Stream Produced................................................ 33

Figure 10: Comparison of the Volume \% Liquid. ....................................................... 33

Figure 11: Comparison of the Compressibility Factor of Gas (Z) 2p........................... 34

Figure 12: Comparison of the Molecular Weight of the Heptane plus........................... 35

Figure 13: Comparison of the Specific Gravity of Heptane plus................................. 35

Figure 14: Comparisons the Compositional Analysis for Rapid River 35 Field. ............ 45

Figure 15: Comparisons the Compositional Analysis for Cold Spring 12 Field ............. 45

Figure 16: Comparisons the Compositional Analysis for Chester 15 Field .................... 46

Figure 17: Comparisons the Compositional Analysis for Khuff 4 Field. ........................ 46

Figure 18: Comparisons the Compositional Analysis for Dakhni Field......................... 47 


\section{LIST OF TABLES}

Table 1: Ahmed Extend Method S Coefficient Values of Condensate Systmes. ............. 13

Table 2: Marching Technique S's Coefficient Values of Condensate Systems................ 13

Table 3: Compositional Analysis \& Lab Data of Pazanan Fluid.................................... 15

Table 4: Compositional Analysis \& Lab Data of Rapid River 35 Fluid......................... 15

Table 5: Compositional Analysis \& Lab Data of Cold Spring 12 Fluid.......................... 16

Table 6: Compositional Analysis \& Lab Data of Chester 15 Fluid................................. 17

Table 7: Compositional Analysis \& Lab Data of Khuff 4 Fluid.................................... 18

Table 8: Compositional Analysis \& Lab Data of Dakhni Fluid. .................................... 18

Table 9: The Prediction Results of Katz's Method.......................................................... 20

Table 10: The Prediction Results of Ahmed's Method. ............................................. 20

Table 11: The Prediction Results of Marching Technique. .......................................... 21

Table 12: Experimental and Predicted Extend Compositional Analysis of C7+ of Pazanan

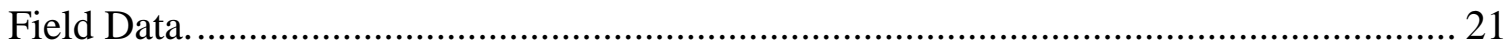

Table 13: S Coefficient Values of 4-Coeffient Method................................................. 23

Table 14: The Compositional Analysis for $\mathrm{n}=30$ for Pazanan Sample using 4-Coefficient

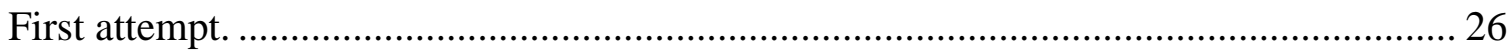

Table 15: The Compositional Analysis for $\mathrm{n}=26$ for Pazanan Sample using 4-Coefficient

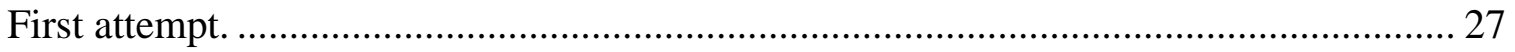

Table 16: The Comparison of the Splitting methods with the proposed Methodology.... 28

Table 17: The Summary of Gas Deplition Calculations and the Absulute Differnce

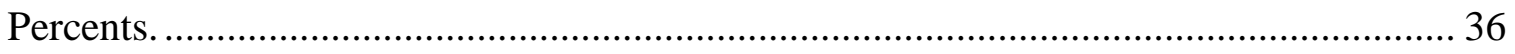

Table 18: Comparisons the Compositional Analysis for Rapid River 35 Field. .............. 40

Table 19: Comparisons the Compositional Analysis for Cold Spring 12 Field. ............. 41

Table 20: Comparisons the Compositional Analysis for Chester 15 Field....................... 42

Table 21: Comparisons the Compositional Analysis for Khuff 4 Field. ......................... 43

Table 22: Comparisons the Compositional Analysis for Dakhni Field........................... 44 


\section{NOMENCLATURE}

a

A

API

b

B

$\mathrm{C}$

$\mathrm{C}_{1}$

$\mathrm{C}_{2}$

$\mathrm{C}_{3}$

$\mathrm{C}_{6}$

$\mathrm{C}_{7+}$

$\mathrm{C}_{8}$

$\mathrm{C}_{9}$

$\mathrm{C}_{10}$

$\mathrm{C}_{\mathrm{n}+}$

$\mathrm{CO}_{2}$

EOS

$\mathrm{iC}_{4}$

$\mathrm{iC}_{5}$

GOR

$\mathrm{HC}$

$\mathrm{m}$

$\mathrm{MW}_{\mathrm{n}}$

$\mathrm{MW}_{\mathrm{n}+}$

$\mathrm{MW}_{(\mathrm{n}+1)+}$

n

$\mathrm{N}_{2}$

$\mathrm{nC}_{4}$

$\mathrm{nC}_{5}$
Equation of state constant

Lohrenz's \& Pederson's equations constant

American Petroleum Institute gravity

Equation of state constant

Lohrenz's \& Pederson's equations constant

Carbon

Methane

Ethane

Propane

Hexane

Heptane plus

Octane

Nonane

Decane

Plus fraction of heavier hydrocarbon

Carbon Dioxide

Equation of state

Iso-Butane

Iso-Pentane

Gas oil ratio

Hydrocarbon

Equation of state parameter

Molecular Weight of $\mathrm{n}$ carbon number

Molecular Weight of $\mathbf{n}$ plus fraction

Molecular Weight of next fraction plus of $\mathrm{n}$ carbon number

Number of Carbon

Nitrogen

Normal-Butane

Normal -Pentane 


\begin{tabular}{ll}
$\mathrm{P}$ & Pressure \\
$\mathrm{Pc}$ & Critical pressure \\
$\mathrm{PVT}$ & Pressure, volume, temperature \\
$\mathrm{R}$ & Gas constant \\
$\mathrm{S}$ & Slopes or Coefficients of Splitting scheme \\
$\mathrm{scf}$ & Standard cubic feet \\
$\mathrm{SCN}$ & Single carbon number \\
$\mathrm{SG}_{7+}$ & Specific gravity of heptane plus fraction \\
$\mathrm{SG}_{\mathrm{n}}$ & Specific gravity of $\mathrm{n}$ carbon number \\
$\mathrm{STB}_{\mathrm{T}}$ & Stock tank barrel \\
$\mathrm{T}$ & Temperature \\
$\mathrm{Tb}$ & Boiling point temperature \\
$\mathrm{Tc}$ & Critical temperature \\
$\mathrm{Tr}$ & Reduced temperature \\
$\mathrm{V}$ & Total phase volume \\
$\mathrm{V}_{\mathrm{m}}$ & Total phase volume of a mixture \\
$\mathrm{Z}$ & Compressibility factor \\
$\mathrm{Z}_{\mathrm{two}-\text { phase }}$ & Two phase deviation factor \\
$\mathrm{Zn}$ & Mole fraction of SCN \\
$\mathrm{Zi}$ & Mole fraction of component i \\
\hline
\end{tabular}

\section{Greek Letters:}

$\alpha \quad$ Equation of state constant

$\gamma_{7+} \quad$ Specific gravity of heptane plus fraction

$\gamma \quad$ Specific gravity of $\mathrm{n}$ carbon number

$\omega \quad$ Acentric factor

\section{Subscripts:}

i

$\mathrm{n}$

$+$

$\%$

\section{Component i}

Carbon number of hydrocarbon component

Plus fraction or last heavier fraction

Percentage 


\section{CHAPTER 1: INTRODUCTION}

The gas condensate fluids are complex mixtures made up of different compounds of varied molecular properties. They are made of hydrocarbons of paraffinic, napthenes, and aromatics. They also may contain non-hydrocarbon compounds. The heavier fractions are usually lumped as heptanes plus, have a significant effect on phase behavior prediction. The extended compositional analysis is necessary to improve the accuracy of the equation of state for predicting phase behavior. It should be estimated if the $\mathrm{C} 7+$ detailed analytical data does not exist. A proper description of physical properties of the heavy hydrocarbon fraction is important to predict the thermodynamics and behavior of the complex hydrocarbon (HC) mixtures by the equation of state (EOS).

It is common procedure for phase behavior prediction to use Equation of State. The EOS determines the equilibrium constants and phase behavior properties. Also, it provides continuity and smoothness of the PVT dependent fluid properties. It is important in compositional analysis to obtain satisfactory agreement between the EOS results and the measured lab data.

The Peng-Robinson equation of estate (P-R EOS) is used because of its ability to provide consistency between phase behavior and densities. However, no equation of state can precisely predict the phase behavior of a hydrocarbon mixture unless the parameters of the equation of state are adjusted. In order to accurately predict the phase behavior, the parameters like molecular weight, accentric factor, critical pressure, critical temperature have to be estimated accurately. During this fine tuning process, the critical properties are adjusted by a trial and error method to arrive at a good match with the standard laboratory values. The P-R EOS has the advantage of giving improved and accurate results for liquid density, dew point and liquid yields at pipeline conditions. 


\section{CHAPTER 2: LITERATURE REVIEW}

\subsection{Retrograde Gas Condensate Reservoir Behavior}

The hydrocarbon reservoirs are porous sections of the sedimentary crust of the earth containing groups of hydrocarbons. The hydrocarbons are a mixture of carbon components and complex molecules. The carbon components are constituting of Methane and Ethane (light fractions); Propanes, butanes, Pentanes and Hexanes (intermediates); and Heptanes and higher (heavier fractions) (Melkaveri, 2007). The complex molecules are Aromatics, Paraffinic and Naphthenic. These HC reservoirs exhibit multiphase behaviors over wide ranges of pressures and temperatures. They may occur in variety states like gaseous, liquid, solid or in various combinations of gas, liquid and/ or solid. Such ranges of conditions can be explained with the Pressure-Temperature (P-T) phase diagram as shown in Figure 1.

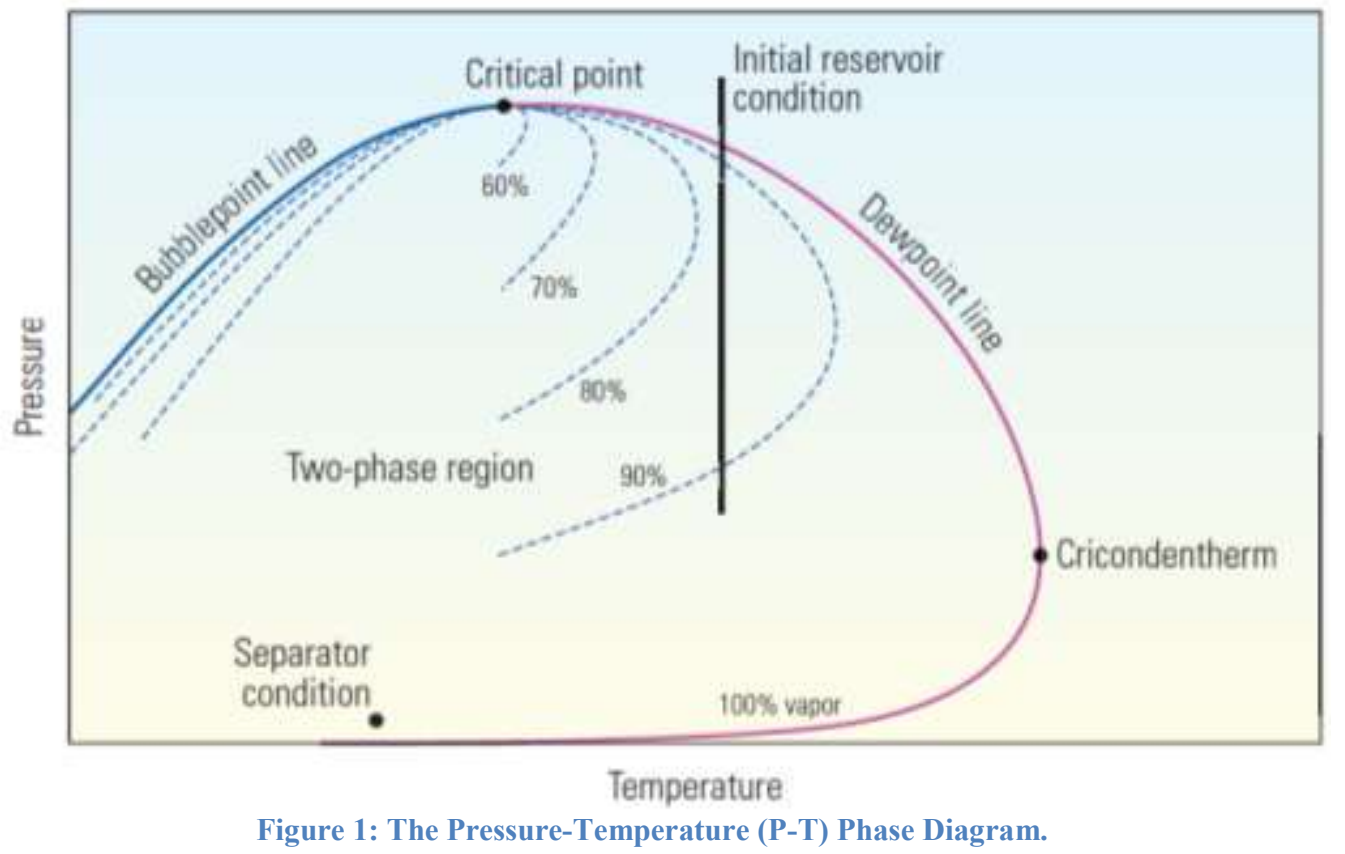

In the P-T Phase diagram (Ahmed, 2007), the area enclosed by the bubble point curve and dew point curve indicate the presence of hydrocarbons in liquid as well as gaseous state. The curves represented by the broken lines indicate the percentage of liquid hydrocarbon volume for any pressure and temperature. If the reservoir temperature, $\mathrm{T}$, lies between the critical temperature, $T_{c}$ and cricondentherm $T_{c t}$ of the reservoir 
fluid, the reservoir is classified as a retrograde gas condensate reservoir. This type of reservoirs is typically composed of $70 \mathrm{~mol} \%$ of Methane, $22 \mathrm{~mol} \%$ of Intermediates and $8 \mathrm{~mol} \%$ of Heptane plus.

In most gas condensate reservoirs, the condensed liquid volume rarely exceeds more than $19 \%$ of the pore volume (Ahmed, 2007). It should be recognized that around the wellbore where the pressure drop is high; enough liquid dropout might accumulate to give two-phase flow of gas and retrograde liquid. The associated physical characteristics of this type of hydrocarbons are:

- GORs are between 8,000 and 70,000 scf/STB.

- Condensate gravity above $50^{\circ} \mathrm{API}$.

- Stock-tank liquid is usually water-white or slightly colored.

There is a fairly sharp dividing line between oil and condensate from a compositional standpoint. Reservoir fluids that contain heptane and heavier in concentrations of more than $12.5 \mathrm{~mol} \%$ are almost always in the liquid phase in the reservoir. Oils have been observed with heptane and heavier concentrations as low as $10 \%$ and condensates as high as $15.5 \%$.

\subsection{Equation of State}

The equation of state is a thermodynamic equation describing the state of matter under a given set of physical conditions. It provides a mathematical relationship between two or more state functions associated with the matter, such as its temperature, pressure or volume. The equations of state are useful in describing the properties of fluids, mixtures of fluids and solids. They provide continuity and smoothness of PVT fluid dependent properties (Malik, 1990). They are also useful in determining the saturation pressure for reservoir fluids (Melkaveri, 2007). Moreover, they are used to find out the partial molar volume of the vapor and liquid phase's components which leading to determine the 
equilibrium constants. Existing of the computer software helps in using the EOS to predict the reservoirs' phase behavior recently.

The first EOS was developed in 1873 by Van-der-Waals and that formed the basis for following equations of state developed such as Peng-Robinson, Redlich-Kwong, SoaveRedlich-Kwong and other equations of state (Van-der-Waals, 1873). The Van-der-Waals EOS successfully provided the continuity from gas to liquid state. Peng-Robinson (P-R EOS) and Soave-Redlich-Kwong (S-R-K EOS) are couple of widely used equations of state. However, in order for an EOS to predict the phase behavior, the parameters present in the EOS should be fine tuned. Fine tuning the parameters involves adjusting the critical properties. This is done usually so as to obtain a good density match.

\subsubsection{Van-der-Waals EOS}

Van-der-Waals (1873) added a correction factor to the ideal gas law to account the volume of the molecules and the attraction force and distance between them. The Vander-Waals equation is the simplest EOS that uses the $\mathrm{T}_{\mathrm{c}}$ and $\mathrm{P}_{\mathrm{c}}$ for each component a and

$\mathrm{b}$ in the equation:

$$
P=\frac{R T}{V-b}-\frac{a}{V^{2}}
$$

At critical point, the values of $\mathrm{a}$ and $\mathrm{b}$ are:

$$
\begin{aligned}
& a=\frac{27}{64} \frac{R^{2} T_{c}^{2}}{P_{c}}=0.421875 \frac{R^{2} T_{c}{ }^{2}}{P_{c}} \\
& b=\frac{R T_{c}}{8 P_{c}}=0.125 \frac{R T_{c}}{P_{c}}
\end{aligned}
$$

Where:

$\mathrm{P}=$ Pressure, psia.

$\mathrm{T}=$ Temperature, ${ }^{\circ} \mathrm{R}$.

$\mathrm{V}=$ Volume, $\mathrm{ft}^{3}$.

$\mathrm{R}=$ Universal Gas Constant, $10.731 \mathrm{ft}^{3} \mathrm{psi}^{\circ} \mathrm{R}^{-1} \mathrm{lb}-\mathrm{mol}^{-1}$.

$\mathrm{T}_{\mathrm{c}}=$ Critical Temperature, ${ }^{\circ} \mathrm{R}$.

$\mathrm{P}_{\mathrm{c}}=$ Critical Pressure, psia. 


\subsubsection{Redlich-Kwong EOS}

Redlich and Kwong (1949) introduced a first major extension of Van-der-Waals' EOS.

The simplest form of R-K EOS is:

$$
P=\frac{R T}{V_{m}-b}-\frac{a}{\sqrt{T} V_{m}\left(V_{m}+b\right)}
$$

Whereas the values of $\mathrm{a}$ and $\mathrm{b}$ are:

$$
\begin{aligned}
& a=\frac{0.42748 R^{2} T_{c}^{2.5}}{P_{c}} \\
& b=\frac{0.08662 R T_{c}}{P_{c}}
\end{aligned}
$$

\subsubsection{Soave-Redlich-Kwong EOS}

Soave (1972) modified the R-K EOS in order to estimate both vapor and liquid properties and the behavior of heptanes plus components by predicting molecular weight, liquid density, and boiling point. The S-R-K EOS is presented by the following equation

$$
P=\left(\frac{R T}{V-b}\right)-\left(\frac{a \alpha}{V(V+b)}\right)
$$

The parameter $\alpha$ is the dimensionless factor which becomes unity at critical pressure and is defined by the expression

$$
\alpha=\left(1+\mathrm{m}\left(1-\mathrm{T}_{\mathrm{r}}^{0.5}\right)\right)^{2}
$$

The parameter $\mathrm{m}$ is correlated with acentric factor $\omega$ and is given as

$$
\mathrm{m}=0.480+1.574 \omega-0.176 \omega^{2}
$$

Where:

$T_{r}=\frac{T}{T_{c}}$

$a$ and $b$ are equals to the values of R-K EOS values.

$\omega$ is the acentric factor for the species. 


\subsubsection{Peng-Robinson EOS}

The Peng-Robinson EOS was published in 1976 to overcome the weaknesses of the S-RK EOS (Peng \& Robinson, 1976; Robinson \& Peng, 1978). The main advantage of the P$\mathrm{R}$ EOS is that it can be used to predict the liquid density. The equation can be described as follows:

$$
P=\frac{R T}{V_{m}-b}-\frac{a \alpha}{V_{m}^{2}+2 b V_{m}-b^{2}}
$$

At critical point, the results equal to:

$$
\begin{aligned}
& a=\frac{0.45724 R^{2} T_{c}^{2}}{P_{c}} \\
& b=\frac{0.07780 R T_{c}}{P_{c}}
\end{aligned}
$$

The parameter $\alpha$ is defined by the expression:

$$
\alpha=\left(1+\mathrm{m}\left(1-\mathrm{T}_{\mathrm{r}}^{0.5}\right)\right)^{2}
$$

Where $\mathrm{m}$ is a constant calculated by accentric factor equation as follows:

$$
m=0.37464+1.54226 \varpi-0.26992 \varpi^{2}
$$

The P-R EOS achieved goals after development are:

1. The EOS parameters are expressible in terms of critical properties and acentric factor.

2. The model provides reasonable accuracy near the critical point, particularly for calculating the compressibility factor and liquid density.

3. The EOS is applicable to all calculations of all fluid properties in natural gas processes.

\subsection{Predicting the Phase Behavior of Hydrocarbon Systems Using P-R EOS}

Predicting the phase behavior of the reservoir fluid needs an EOS and the extended composition analysis of the heavy fractions of the reservoir fluid. A proper description of physical properties of the heavy hydrocarbon fraction is important to predict the thermodynamics and behavior of the complex HC mixtures by the EOS. These fractions 
are usually lumped as the heptanes plus group (C7+). The extended composition analysis should be estimated if the $\mathrm{C} 7+$ detailed analytical data does not exist. Using the extended compositional analysis improves the accuracy of the EOS in predicting the phase behavior.

The PR-AGA phase behavior package is a PC programmed version of the P-R EOS. It has a help document that allows modifying existing data files (Aminian, 1989). This software incorporates the P-R EOS using built in properties of the hexanes plus (C6+). This simulation program is capable to perform the independent equilibrium calculations which will determine the retrograde dew point pressure. Also, more major options are available in the program with more calculations can be performed. The package has in input data file generator program developed for input data preparation. The data which given by the user is stored and the program sets up an input file. The input file is then run with a command line and the program generates an output file predicting the phase behavior for the hydrocarbon system. All calculations are based on the P-R EOS.

\subsubsection{The Input File for the PR-AGA Phase Behavior Package}

The program starts by listing the different options that are available and allows the user to create and name a file. This is followed by a series of questions including the number of streams in the feed, number of components, number of fractions higher than C6, the correlation to be used and the type of calculations. The components present in the mixture are to be identified and assigned a title. The relative molar rate of the stream is to be entered and the mole fractions of all the components are given to the program. The pressure, temperature data at which the phase behavior is to be determined is then given to the program. At the end of the data input, a file is created and saved under a file name with all the pertinent information. The program is set to use methane interaction parameters using the density correlations. The mole fractions are next displayed followed by the pressure and temperature conditions. A typical input file is shown in Figure 2.

In some cases, it is needed to adjust EOS parameters to accurately predict the phase behavior of a complex $\mathrm{HC}$ mixture at reservoir conditions. These parameters are boiling 
point, specific gravity, critical temperature, critical pressure and acentric factor. Also, the interaction coefficients may need to be adjusted (Katz \& Firoozabadi, 1978; Crasten slotPetersen, 1989). This type of input file is shown in Figure 3.

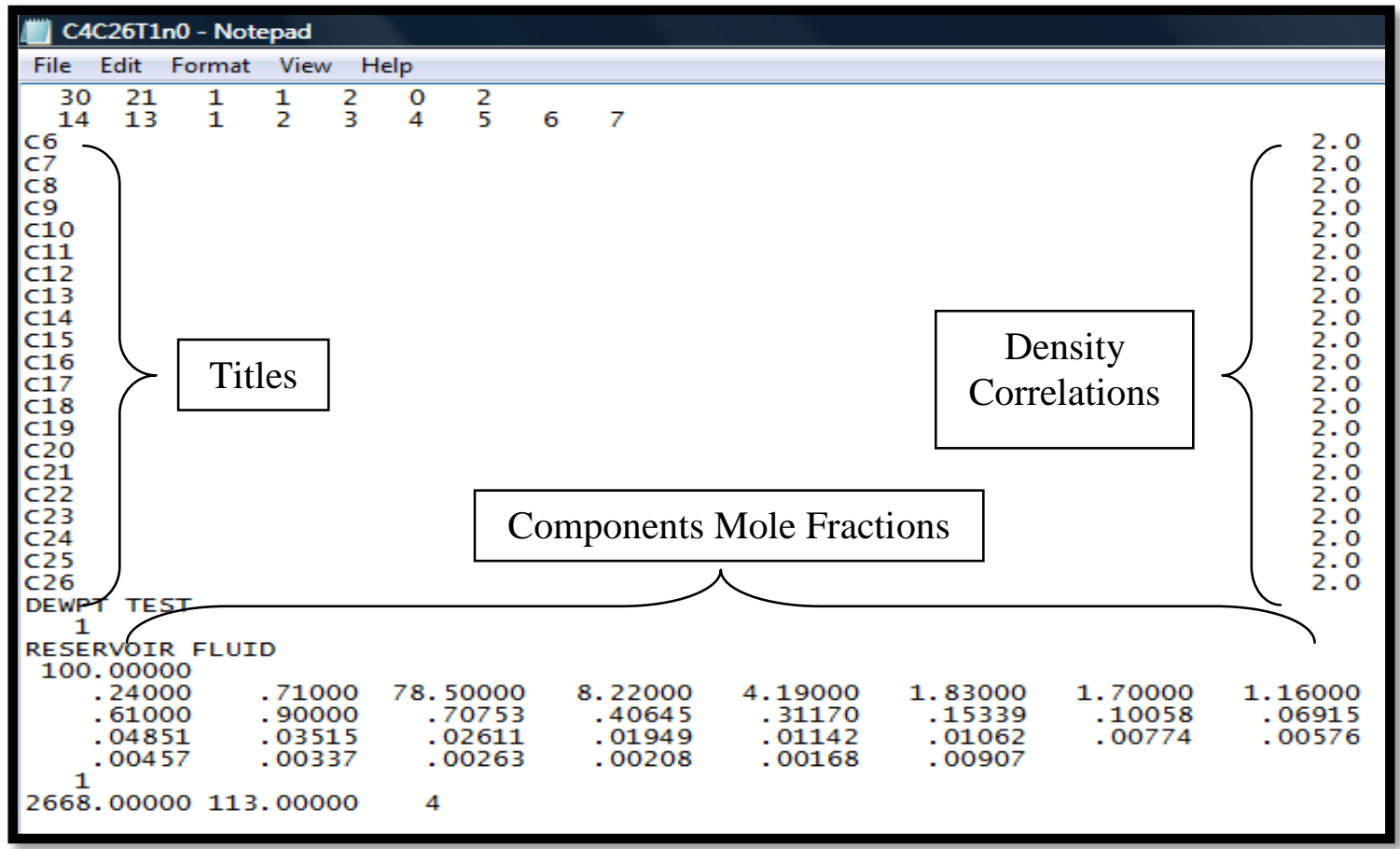

Figure 2: The Typical Input File of the PR-AGA Phase Behavior.

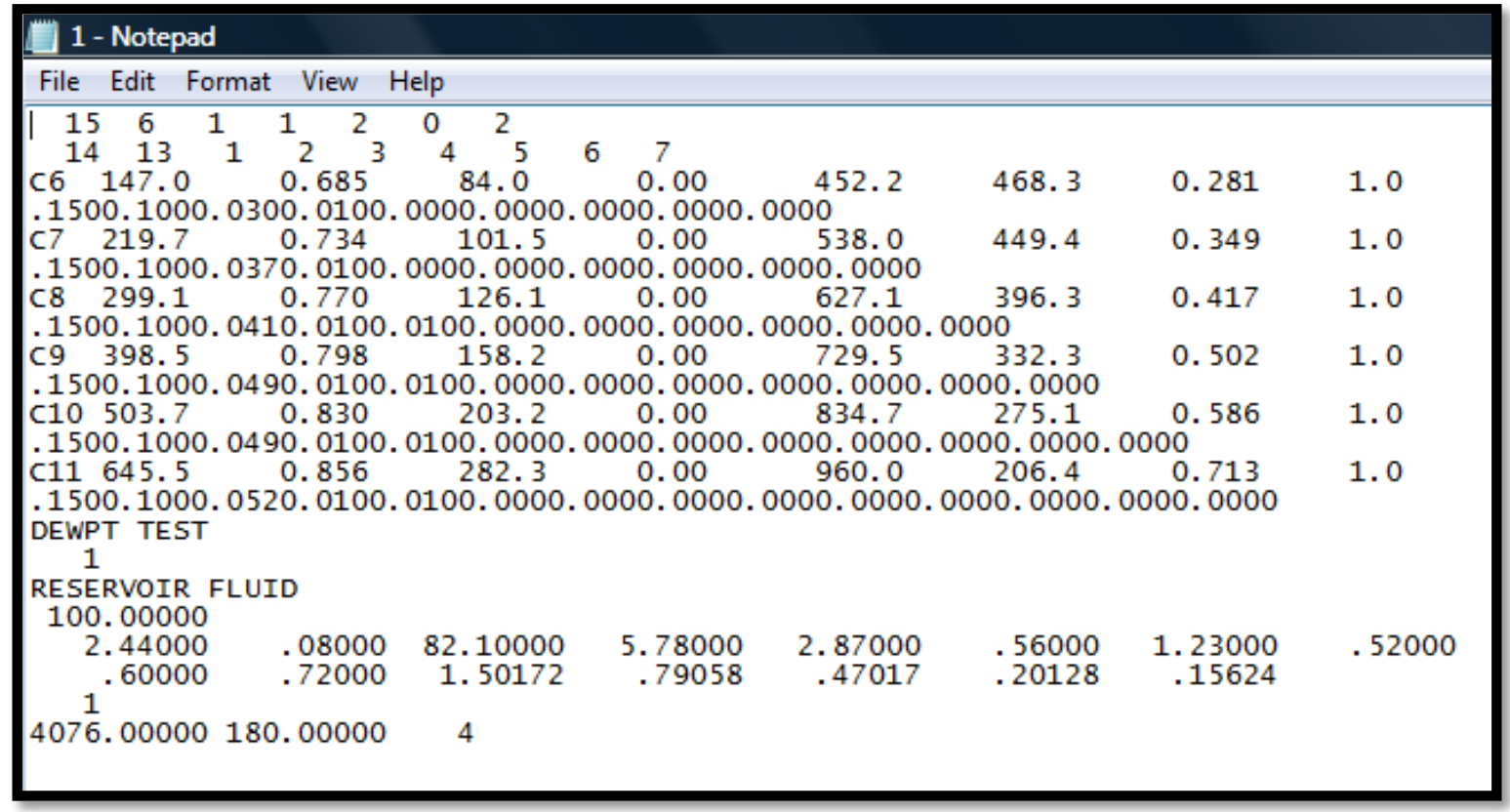

Figure 3: Typical Input File with Critical Properties and Interaction Coeffcients. 


\subsubsection{The Output File for the PR-AGA Phase Behavior Package}

The input file is then run with the help of a command with the file name. The resulting file gives out the phase behavior of all the mixtures at the requested pressures and temperatures. The output includes the physical properties, the interaction parameters, the stream mixed molar rates, the retrograde dew point pressure, reservoir temperature, total mole rate, molecular weights, densities, and other values upon requested. The values thus obtained from the program are compared with the standard laboratory values. A typical output file is shown in Figure 4.

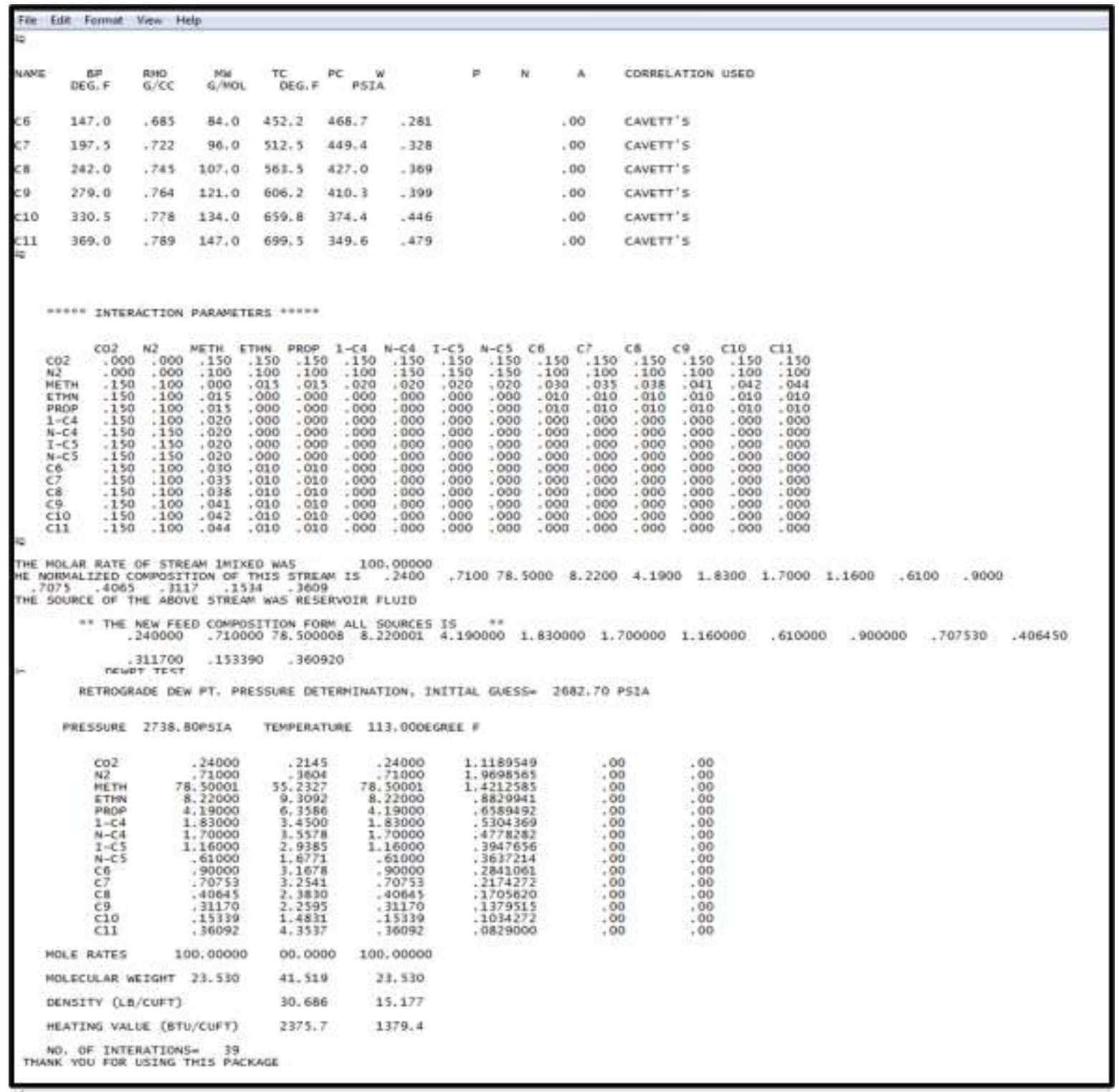

Figure 4: The Typical Output File of the PR-AGA Phase Behavior. 


\subsection{Extended Compositional Analysis Methods}

For an equation of state to be able to predict the phase behavior accurately, the extended composition analysis or break down of the $\mathrm{C}_{7+}$ is required. The heavy fractions characterization procedure has a significant effect on the prediction of the equations of state. In many cases, this heavy ends may have only few measured properties available like Average Molecular weight and Average Specific Gravity. The heavy fractions are difficult to characterize without an extended laboratory analysis. This problem can be substantially reduced by "splitting" or "breaking down" the plus fraction into a manageable number of fractions (pseudo components) for equation-of-state calculations.

An accurate description of pseudo-component compositions or Single Carbon Number $(\mathrm{SCN})$ fractions is an integral part of the reservoir fluids characterization process. These data are applied with Equations of State (EOS) to evaluate gas condensate reserves and production for field development and surface facility design. Very often the required extended compositional data are unavailable experimentally and are generated from mathematical relationships called splitting schemes. Splitting schemes are included in every EOS simulation model to extend the composition of the plus fraction.

Splitting schemes refer to the procedures of dividing the heptanes-plus fractions into hydrocarbon groups with a single carbon number (C7, C8, C9, etc.), described by the same physical properties used for pure components (Ahmed, 2007). There are several schemes for extending the molar distribution behavior of $\mathrm{C} 7+$ in terms of mole fraction as a function of molecular weight or number of carbon atoms. The most used schemes are Katz, Lohrenz, Pedersen, Ahmed and Marching methods.

Three important requirements should be satisfied when applying any splitting model:

1. The sum of the mole fractions of the individual pseudo components is equal to the mole fraction of $\mathrm{C} 7+$ which can be expressed as following:

$$
\sum_{n=7}^{n+} z_{n}=z_{7+}
$$


2. The sum of the products of the mole fraction and the molecular weight of the individual pseudo components is equal to the product of the mole fraction and molecular weight of $\mathrm{C} 7+$. This can be expressed mathematically as:

$$
\sum_{n=7}^{n+}\left[z_{n} M_{n}\right]=z_{7+} M_{7+}
$$

3. The sum of the product of the mole fraction and molecular weight divided by the specific gravity of each individual component is equal to that of $\mathrm{C} 7+$. The following formula show this expression:

$$
\sum_{n=7}^{n+} \frac{z_{n} M_{n}}{\gamma_{n}}=\frac{z_{7+} M_{7+}}{\gamma_{7+}}
$$

Where:

$z_{7+}=$ mole fraction of $\mathrm{C}_{7+}$,

$n=$ number of carbon atoms,

$n_{+}=$last hydrocarbon group in the $\mathrm{C}_{7+}$ with $n$ carbon atoms,

$z_{n}=$ mole fraction of pseudo component with $n$ carbon atoms,

$M_{7+}, \gamma_{7+}=$ measured molecular weight and specific gravity of $\mathrm{C}_{7+}$,

$M_{n}, \gamma_{n}=$ molecular weight and specific gravity of the pseudo component with $n$ carbon atoms.

\subsubsection{Katz's Splitting Scheme}

Katz (1983) presented an easy-to-use graphical correlation for breaking down into pseudo components the $\mathrm{C} 7+$ fraction present in condensate systems. On a semi log scale, the mole percent of each constituent of the $\mathrm{C} 7+$ fraction versus the carbon number in the fraction was plotted. The resulting relationship can be conveniently expressed mathematically by the following expression:

$$
z_{n}=1.38205 z_{7+} e^{-0.25903 n}
$$




\subsubsection{Lohrenz's Splitting Scheme}

Lohrenz, Bra and Clark (1964) proposed that the heptanes-plus fraction could be divided into pseudo components with carbon number ranges from 7 to 40. The use of Lohrenz's Splitting Scheme assumes that some molar fractions beyond C6 are known in order to determine the constants $\mathrm{A} \& \mathrm{~B}$. They mathematically stated that the mole fraction $z_{n}$ is related to its number of carbon atoms $n$ and the mole fraction of the hexane fraction $z 6$ by the expression:

$$
z_{n}=z_{6} e^{A(n-6)^{2}+B(n-6)}
$$

Where:

$A$ and $B$ are constants determined such that the three above requirements are satisfied.

\subsubsection{Pedersen's Splitting Scheme}

Pedersen, Thomassen, and Fredenslund (1982) proposed that an exponential relationship exists between the mole fraction of a component and the corresponding carbon number. The Pedersen's Splitting Scheme was able to be used to calculate the molar fractions if some molar fractions beyond C6 are available order to determine the constants A \& B. They expressed this relationship mathematically in the following form:

$$
z_{n}=e^{(n-A) / B}
$$

Where:

$A$ and $B$ constants determined by at least-squares fit to the molar distribution of the lighter fractions.

\subsubsection{Ahmed's Extend Method}

Ahmed, Cady and Story $(1984,1985)$ developed a simplified method for splitting the C7+ fraction into pseudo components. The only required data for the proposed method are the molecular weight and the total mole fraction of the heptanes-plus fraction. The splitting scheme is based on calculating the mole fraction, $z_{n}$, at a progressively higher number of carbon atoms. The extraction process continues until the sum of the mole 
fraction of the pseudo components equals the total mole fraction of the heptanes plus $\left(z_{7+}\right)$

$$
z_{n}=z_{n+}\left[\frac{M_{(n+1)+}-M_{n+}}{M_{(n+1)+}-M_{n}}\right]
$$

Where:

$M_{n+}=$ molecular weight of the $n_{+}$fraction as calculated by the following:

$$
M_{(n+1)+}=M_{7+}+S(n-6)
$$

Where:

$S$ is a coefficient of the equation with the values given below.

Table 1: Ahmed Extend Method S Coefficient Values of Condensate Systmes.

\begin{tabular}{|c|c|}
\hline No. of Carbon Atoms & S's coefficient Values \\
\hline$n \leq 8$ & 15.5 \\
\hline$n>8$ & 17.0 \\
\hline
\end{tabular}

It was noticed that Ahmed Extend Method is utilizing constant set of slopes which are not true for all condensates and may ultimately lead to misleading conclusions.

\subsubsection{Marching Technique}

Hosein, McCain and Jagai (2008) created a four coefficient model. This model based on observation that the $\mathrm{HC}$ systems exhibit a molar distribution that is relative to the average molecular weight and specific gravity of the plus fraction (Hosein, 2003). It uses Ahmed procedure in all calculations with a different in the $\mathrm{S}$ coefficient values applied to the SCN beyond the heptane. The S's coefficient of Marching Technique values are given in following table.

Table 2: Marching Technique S's Coefficient Values of Condensate Systems.

\begin{tabular}{|c|c|}
\hline No. of Carbon Atoms & S's coefficient Values \\
\hline$n=8$ & 11.4 \\
\hline $8<n<13$ & 15.6 \\
\hline$n=13$ & 11.3 \\
\hline$n>13$ & 12.9 \\
\hline
\end{tabular}




\section{CHAPTER 3: THE METHODOLOGY}

A methodology was developed to perform the research and achieve the objective of predicting the extended composition of gas condensate fluid. The first step was to collect data from various geographically spread fields. The second step was to examine and evaluate the accuracy of the available splitting models to bench mark the outcomes of this research. The third step was to develop a systematic methodology for splitting the heptane plus fraction. Finally, the result of this research was verified to test its applicability.

\subsection{Data Collection}

In this research, six samples have been used in order to evaluate various splitting schemes. These samples have laboratory extended data available which will be used to compare with results from various schemes. These samples are from various gas condensate fields from different parts of the world as discussed in the following sections:

\subsubsection{Pazanan Gas Condensate Field, Iran}

Pazanan reservoir at a distance of $25 \mathrm{~km}$ form Behbahan is situated in west of Iran with an approximate length of $60 \mathrm{~km}$, width of 4-6 km and depth of $2 \mathrm{~km}$ (Fairoozabadi, Hekim \& Katz, 1978). The discovery of the field was in 1937 and existence of hydrocarbons in 1961. At present, the field is considered as a gas condensate reservoir with a thin layer of oil column. The drilling of gas wells with the purpose of injection to the Gachsaran reservoir (Asmari formation) was started in 1974 and finally continuous gas production from gas dome of Asmari formation in 1977. The compositional analysis and the lab data of Pazanan fluid are listed in Table 3. 
Table 3: Compositional Analysis \& Lab Data of Pazanan Fluid.

\begin{tabular}{|c|c|}
\hline Component & Mole Fraction \\
\hline $\mathbf{C O}_{2}$ & 2.44 \\
\hline $\mathrm{N}_{2}$ & $\mathbf{0 . 0 8}$ \\
\hline $\mathrm{C}_{1}$ & $\mathbf{8 2 . 1}$ \\
\hline $\mathrm{C}_{2}$ & $\mathbf{5 . 7 8}$ \\
\hline $\mathrm{C}_{3}$ & $\mathbf{2 . 8 7}$ \\
\hline $\mathrm{iC}_{4}$ & $\mathbf{0 . 5 6}$ \\
\hline $\mathrm{nC}_{4}$ & $\mathbf{1 . 2 3}$ \\
\hline $\mathrm{iC}_{5}$ & $\mathbf{0 . 5 2}$ \\
\hline $\mathrm{nC}_{5}$ & $\mathbf{0 . 6 0}$ \\
\hline $\mathrm{C}_{6}$ & $\mathbf{0 . 7 2}$ \\
\hline $\mathrm{C}_{7+}$ & $\mathbf{3 . 1 2}$ \\
\hline
\end{tabular}

\begin{tabular}{|c|c|}
\hline \multicolumn{2}{|c|}{ Properties of Heptane Plus } \\
\hline $\mathbf{C}_{7+}$ Molecular Weight & 132 \\
\hline $\mathbf{C}_{7+}$ Specific Gravity & $\mathbf{0 . 7 7 4}$ \\
\hline Dew Point Pressure & $\mathbf{4 0 7 6} \mathrm{psia}$ \\
\hline Reservoir Temperature & $180.5 \mathrm{deg} \mathbf{F}$ \\
\hline
\end{tabular}

\subsubsection{Rapid River 35 Gas Condensate Field, Michigan, USA}

Rapid River 35 is a gas condensate field located in the Kalkaska County in northern of Michigan in USA (Katz, Herzog \& Hekim, 1981). The depth of the reservoir is at $6400 \mathrm{ft}$. The field was discovered in 1973. The gas wells were stared drilled in 1980 for producing from the Niagara formation. The compositional analysis and the lab data of the Rapid River 35 fluid are listed in Table 4.

Table 4: Compositional Analysis \& Lab Data of Rapid River 35 Fluid.

\begin{tabular}{|c|c|}
\hline Component & Mole Fraction \\
\hline $\mathbf{C O}_{2}$ & 1.15 \\
\hline $\mathbf{N}_{2}$ & $\mathbf{0 . 1 4}$ \\
\hline $\mathrm{C}_{1}$ & $\mathbf{8 4 . 1 5}$ \\
\hline $\mathrm{C}_{2}$ & 4.79 \\
\hline $\mathrm{C}_{3}$ & $\mathbf{2 . 5 6}$ \\
\hline $\mathrm{iC}_{4}$ & $\mathbf{2 . 0 5}$ \\
\hline $\mathrm{nC}_{4}$ & $\mathbf{1 . 4 7}$ \\
\hline $\mathrm{iC}_{5}$ & $\mathbf{0 . 8 8}$ \\
\hline $\mathrm{nC}_{5}$ & $\mathbf{0 . 3 7}$ \\
\hline $\mathrm{C}_{6}$ & $\mathbf{0 . 6 1}$ \\
\hline $\mathrm{C}_{7+}$ & $\mathbf{1 . 8 3}$ \\
\hline
\end{tabular}




\begin{tabular}{|c|c|}
\hline \multicolumn{2}{|c|}{ Properties of Heptane Plus } \\
\hline $\mathbf{C}_{7+}$ Molecular Weight & 129 \\
\hline $\mathbf{C}_{7+}$ Specific Gravity & $\mathbf{0 . 7 7 3}$ \\
\hline Dew Point Pressure & 3309 psia \\
\hline Reservoir Temperature & $114 \mathrm{deg}$ F \\
\hline
\end{tabular}

\subsubsection{Cold Spring 12 Gas Condensate Field, Michigan, USA}

Cold Spring 12 is a gas condensate field located in the Kalkaska County in northern of Michigan in USA (Katz et al., 1981). The field was discovered in 1973. Seven years later, the field was start producing from Niagara formation at depth of $6600 \mathrm{ft}$. The compositional analysis and the lab data of the Cold Spring 12 gas condensate fluid are listed in Table 5.

Table 5: Compositional Analysis \& Lab Data of Cold Spring 12 Fluid.

\begin{tabular}{|c|c|}
\hline Component & Mole Fraction \\
\hline $\mathbf{C O}_{2}$ & $\mathbf{0 . 0 0 1}$ \\
\hline $\mathbf{N}_{2}$ & $\mathbf{0 . 7 9}$ \\
\hline $\mathbf{C}_{1}$ & $\mathbf{8 0 . 0 9 9}$ \\
\hline $\mathbf{C}_{2}$ & 7.46 \\
\hline $\mathbf{C}_{3}$ & 3.70 \\
\hline $\mathbf{i C}_{4}$ & 1.75 \\
\hline $\mathbf{n C}_{4}$ & 1.30 \\
\hline $\mathbf{i C}_{5}$ & $\mathbf{0 . 8 4}$ \\
\hline $\mathbf{n C}_{5}$ & $\mathbf{0 . 3 9}$ \\
\hline $\mathbf{C}_{6}$ & $\mathbf{0 . 8 4}$ \\
\hline $\mathbf{C}_{7+}$ & 2.83 \\
\hline
\end{tabular}

\begin{tabular}{|c|c|}
\hline \multicolumn{2}{|c|}{ Properties of Heptane Plus } \\
\hline $\mathbf{C}_{7_{+}}$Molecular Weight & 125 \\
\hline $\mathrm{C}_{7+}$ Specific Gravity & $\mathbf{0 . 7 7 3}$ \\
\hline Dew Point Pressure & $3620 \mathrm{psia}$ \\
\hline Reservoir Temperature & $114 \mathrm{deg} \mathbf{F}$ \\
\hline
\end{tabular}

\subsubsection{Chester 15 Gas Condensate Field, Michigan, USA}

Chester 15 is a gas condensate field located in the Otsego County in northern of Michigan in USA (Katz et al., 1981). The depth of targeted formation was $6130 \mathrm{ft}$. The 
field was discovered in 1970. In 1971, the field started producing from the Niagaranpinnacle reef. The compositional analysis and lab data of the Chester 15 fluid are listed in Table 6.

Table 6: Compositional Analysis \& Lab Data of Chester 15 Fluid.

\begin{tabular}{|c|c|}
\hline Component & Mole Fraction \\
\hline $\mathbf{C O}_{2}$ & 0.24 \\
\hline $\mathrm{N}_{2}$ & $\mathbf{0 . 7 1}$ \\
\hline $\mathrm{C}_{1}$ & $\mathbf{7 8 . 5 0}$ \\
\hline $\mathrm{C}_{2}$ & $\mathbf{8 . 2 2}$ \\
\hline $\mathrm{C}_{3}$ & $\mathbf{4 . 1 9}$ \\
\hline $\mathrm{iC}_{4}$ & $\mathbf{1 . 8 3}$ \\
\hline $\mathrm{nC}_{4}$ & 1.70 \\
\hline $\mathrm{iC}_{5}$ & 1.16 \\
\hline $\mathrm{nC}_{5}$ & $\mathbf{0 . 6 1}$ \\
\hline $\mathrm{C}_{6}$ & $\mathbf{0 . 9 0}$ \\
\hline $\mathrm{C}_{7+}$ & 1.94 \\
\hline
\end{tabular}

\begin{tabular}{|c|c|}
\hline \multicolumn{2}{|c|}{ Properties of Heptane Plus } \\
\hline C $_{7+}$ Molecular Weight & 123 \\
\hline C $_{7+}$ Specific Gravity & 0.756 \\
\hline Dew Point Pressure & 2668 psia \\
\hline Reservoir Temperature & 113 deg F \\
\hline
\end{tabular}

\subsubsection{Khuff 4 Gas Condensate Field, Qatar}

Khuff 4 is a gas condensate field of Khuff reservoir located offshore in the northwest of Qatar (Almaary, 1983). The gas field covers an area of 9700 square kilometers, of which 3700 square kilometers (South Pars) is in Iranian territorial waters and 6000 square kilometers (North Dome) is in Qatari territorial waters. The field was discovered in 1971. The field started producing in 1989 from Khuff formation at a depth of 9,400 ft. The North Field Khuff formation is a competent limestone. It is the largest single accumulation of natural gas in the world. The compositional analysis and lab data of the Khuff 4 fluid are listed in Table 7. 
Table 7: Compositional Analysis \& Lab Data of Khuff 4 Fluid.

\begin{tabular}{|c|c|}
\hline Component & Mole Fraction \\
\hline $\mathbf{H}_{2} \mathbf{S}$ & $\mathbf{0 . 5 4}$ \\
\hline $\mathbf{C O}_{2}$ & 1.78 \\
\hline $\mathbf{N}_{2}$ & 3.38 \\
\hline $\mathbf{C}_{1}$ & $\mathbf{8 2 . 7 7}$ \\
\hline $\mathbf{C}_{2}$ & $\mathbf{5 . 2 9}$ \\
\hline $\mathbf{C}_{3}$ & $\mathbf{1 . 9 6}$ \\
\hline $\mathrm{iC}_{4}$ & $\mathbf{0 . 4 2}$ \\
\hline $\mathrm{nC}_{4}$ & $\mathbf{0 . 7 1}$ \\
\hline $\mathrm{iC}_{5}$ & $\mathbf{0 . 2 9}$ \\
\hline $\mathrm{nC}_{5}$ & $\mathbf{0 . 2 9}$ \\
\hline $\mathrm{C}_{6}$ & $\mathbf{0 . 4 2}$ \\
\hline $\mathrm{C}_{7+}$ & $\mathbf{2 . 1 5}$ \\
\hline
\end{tabular}

\begin{tabular}{|c|c|}
\hline \multicolumn{2}{|c|}{ Properties of Heptane Plus } \\
\hline C $_{7+}$ Molecular Weight & 135.6 \\
\hline C $_{7+}$ Specific Gravity & 0.76 \\
\hline Dew Point Pressure & 5120 psia \\
\hline Reservoir Temperature & 220 deg F \\
\hline
\end{tabular}

\subsubsection{Dakhni Gas Condensate Field, Pakistan}

Dakhni (Core laboratory report, 1986) is a gas condensate field located about $135 \mathrm{~km}$ southwest of Islamabad. The field was discovered in February 1983 and came on production in the end of 1989 from Shinwari and Samanasuk formations at a approximate depth of $15900 \mathrm{ft}$. The compositional analysis and lab data of the Dakhni fluid are listed in Table no. 8.

Table 8: Compositional Analysis \& Lab Data of Dakhni Fluid.

\begin{tabular}{|c|c|}
\hline Component & Mole Fraction \\
\hline $\mathbf{H}_{2} \mathrm{~S}$ & $\mathbf{8 . 1 6}$ \\
\hline $\mathrm{CO}_{2}$ & $\mathbf{4 . 4 4}$ \\
\hline $\mathbf{N}_{2}$ & $\mathbf{0 . 7 2}$ \\
\hline $\mathrm{C}_{1}$ & $\mathbf{8 0 . 5 1}$ \\
\hline $\mathrm{C}_{2}$ & 2.67 \\
\hline $\mathrm{C}_{3}$ & $\mathbf{1 . 1 5}$ \\
\hline $\mathrm{iC}_{4}$ & $\mathbf{0 . 2 4}$ \\
\hline $\mathrm{nC}_{4}$ & $\mathbf{0 . 3 0}$ \\
\hline
\end{tabular}




\begin{tabular}{|c|c|}
\hline $\mathbf{i C}_{5}$ & $\mathbf{0 . 1 6}$ \\
\hline $\mathrm{nC}_{\mathbf{5}}$ & $\mathbf{0 . 1 3}$ \\
\hline $\mathrm{C}_{\mathbf{6}}$ & $\mathbf{0 . 2 2}$ \\
\hline $\mathrm{C}_{7+}$ & $\mathbf{1 . 3 0}$ \\
\hline
\end{tabular}

\begin{tabular}{|c|c|}
\hline \multicolumn{2}{|c|}{ Properties of Heptane Plus } \\
\hline $\mathbf{C}_{7+}$ Molecular Weight & 136.7 \\
\hline $\mathbf{C}_{7+}$ Specific Gravity & $\mathbf{0 . 7 9 6}$ \\
\hline Dew Point Pressure & 5668 psia \\
\hline Dew Point Temperature & $220 \mathrm{deg}$ F \\
\hline
\end{tabular}

\subsection{Application of the Existing Techniques}

The extended compositional analysis must be calculated or estimated in the absence of the detailed analytical data. The existing splitting schemes (Katz, Ahmed and Marching) have been used to predicate the compositional distribution of the $\mathrm{C} 7+$ fraction. The results are compared in order to evaluate each scheme. All the splitting methods were test of fluid of Pazanan field. The lab results of heptane plus the Pazanan field are as following:

- $\quad$ Mole Fraction: $\mathrm{Z}_{\mathrm{C} 7+}=3.12$

- Molecular Weight: $\mathrm{MW}_{\mathrm{C} 7+}=132$

- $\quad$ Specific Gravity: $\mathrm{SG}_{\mathrm{C} 7+}=0.774$

- $\quad$ The Retrograde Dew Point Pressure $=4076$ psia

All the splitting schemes are use to spitted the heptane plus to different number of components $(n=15,16,17, \ldots 35)$ and the best results are shown. The following equations are used to calculate the mole fraction, the molecular weight and the specific gravity:

1. The mole fraction of the heptane plus:

$$
Z_{C 7+}=\sum_{n=7}^{n+} z_{n}
$$

2. The molecular weight of the heptane plus: 


$$
M W_{C n+}=\frac{z_{7+} M W_{7+}-\sum_{n=7}^{(n+)-1}\left[z_{n} M W_{n}\right]}{z_{n+}}
$$

3. The specific gravity of the heptane plus:

$$
\gamma_{c n+}=\frac{z_{c n+} M W_{c n+}}{\frac{z_{7+} M w_{7+}}{\gamma_{7+}}-\sum_{n=7}^{(n+)-1} \frac{z_{n} M w_{n}}{\gamma_{n}}}
$$

4. The retrograde dew point pressure is calculated by using the PC version of P-RAGA software.

\subsubsection{Application of Splitting Schemes to Pazanan Field Data}

Table 9 summarizes the prediction results of applying Katz's method to predict the molar distribution of extended $\mathrm{C}_{7+}$. The molar distribution of heptane-plus predicted by Katz's method with 30 components is shown in Table 12 and Figure 5.

Table 9: The Prediction Results of Katz's Method.

\begin{tabular}{|l|c|c|}
\hline Splitting Method & \multicolumn{2}{|c|}{ Katz's Splitting Scheme } \\
\hline Number of Components & \multicolumn{2}{|c|}{30} \\
\hline Calculated Specific Gravity & 0.685 & $-11 \%$ \\
\hline Calculated Retrograde Dew Point Pressure & 4656 psia & $14 \%$ \\
\hline
\end{tabular}

The prediction results of applying Ahmed's method to predict the molar distribution of extended $\mathrm{C}_{7+}$ are summarized in Table 10. The molar distribution of heptane-plus by this method with 30 components is shown in Table 12 and Figure 5.

Table 10: The Prediction Results of Ahmed's Method.

\begin{tabular}{|l|c|c|}
\hline Splitting Method & Ahmed's Extend Method \\
\hline Number of Components & \multicolumn{2}{|c|}{30} \\
\hline Calculated Specific Gravity & 0.782 & $1 \%$ \\
\hline Calculated Retrograde Dew Point Pressure & 4198 psia & $3 \%$ \\
\hline
\end{tabular}


The results of applying Marching method in predicting the molar distribution of extended $\mathrm{C}_{7+}$ are tabulated in Table 11. The molar distribution of heptane-plus by Marching with 30 components is shown in Table 12 and Figure 5.

Table 11: The Prediction Results of Marching Technique.

\begin{tabular}{|l|c|c|}
\hline Splitting Method & \multicolumn{2}{|c|}{ Marching Technique } \\
\hline Number of Components & \multicolumn{2}{|c|}{30} \\
\hline Calculated Specific Gravity & 0.782 & $1.02 \%$ \\
\hline Calculated Retrograde Dew Point Pressure & 4228 psia & $3.73 \%$ \\
\hline
\end{tabular}

Table 12: Experimental and Predicted Extend Compositional Analysis of C7+ of Pazanan Field Data.

\begin{tabular}{|c|c|c|c|c|}
\hline \multirow{2}{*}{ Fraction } & \multicolumn{4}{|c|}{ MOLE FRACTION } \\
\cline { 2 - 5 } & Experimental & Katz's & Ahmed's & Marching \\
\hline \hline C7 & 0.75 & 0.70341 & 0.93903 & 0.74557 \\
\hline C8 & 0.75 & 0.54290 & 0.60366 & 0.82950 \\
\hline C9 & 0.49 & 0.41901 & 0.50881 & 0.41157 \\
\hline C10 & 0.31 & 0.32339 & 0.27522 & 0.28756 \\
\hline C11 & 0.22 & 0.24959 & 0.19265 & 0.20448 \\
\hline C12 & 0.15 & 0.19263 & 0.13987 & 0.11643 \\
\hline C13 & 0.12 & 0.14868 & 0.10306 & 0.12041 \\
\hline C14 & 0.09 & 0.11475 & 0.07796 & 0.08449 \\
\hline C15 & 0.07 & 0.08856 & 0.06020 & 0.06960 \\
\hline C16 & 0.17 & 0.06835 & 0.04665 & 0.05661 \\
\hline C17 & & 0.05275 & 0.03584 & 0.04448 \\
\hline C18 & & 0.04072 & 0.02741 & 0.03383 \\
\hline C19 & & 0.03142 & 0.02071 & 0.02453 \\
\hline C20 & & 0.02425 & 0.01591 & 0.01791 \\
\hline C21 & & 0.01872 & 0.01293 & 0.01425 \\
\hline C22 & & 0.01445 & 0.00982 & 0.00964 \\
\hline C23 & & 0.01115 & 0.00784 & 0.00712 \\
\hline C24 & & 0.00861 & 0.00633 & 0.00529 \\
\hline C25 & & 0.00664 & 0.00520 & 0.00403 \\
\hline C26 & & 0.00513 & 0.00427 & 0.00301 \\
\hline C27 & & 0.00396 & 0.00351 & 0.00222 \\
\hline C28 & & 0.00305 & 0.00293 & 0.00168 \\
\hline C29 & & 0.00236 & 0.00243 & 0.00124 \\
\hline C30 & & 0.04553 & 0.01775 & 0.00455 \\
\hline
\end{tabular}




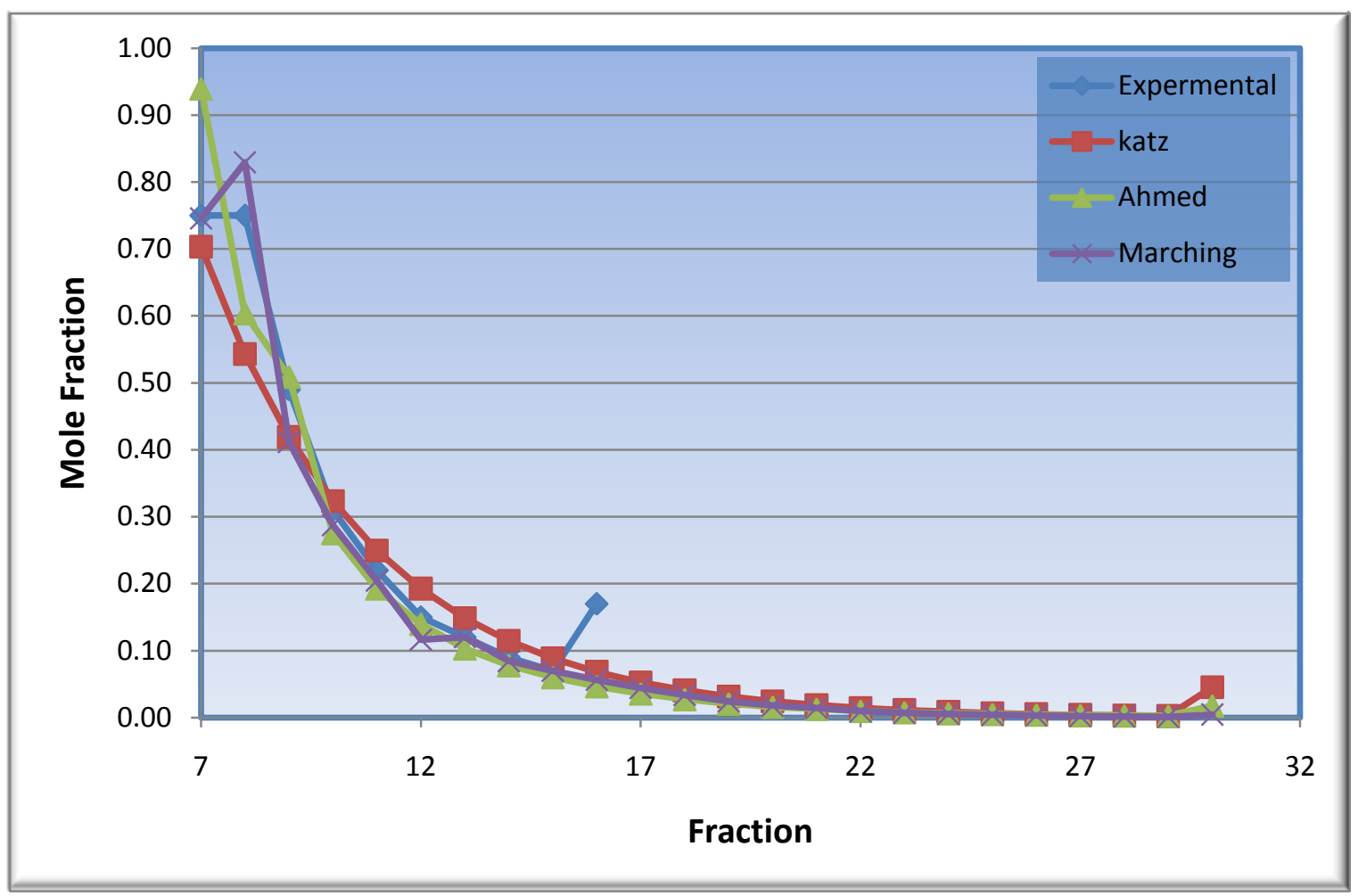

Figure 5: Comparison of various Splitting Scheme results for Pazanan Field Data.

\subsection{Proposed (4-Coefficient) Methodology for Splitting the $\mathbf{C}_{7+}$}

The objective of this study as mentioned is to determine an appropriate method for splitting the heptane plus fraction into $\mathrm{n}$ components in the hydrocarbon systems. The existing methods for predicting the heptane plus fraction compositions have certain limitations. For that, a model has been proposed to overcome these limitations.

The model has been proposed and verified in this study on the basis of the following conditions:

1. The calculated average molecular weight of the heptanes plus based on the estimated extended analysis should match the reported molecular weight.

2. The calculated average specific gravity of the heptanes plus based on estimated extended analysis should match the reported specific gravity of the heptane plus. 
3. The retrograde dew point pressure determined from estimated composite should match the reported value.

The mole fraction, molecular weight, specific gravity and the retrograde dew point pressure of heptanes plus fraction are usually provided with the detailed gas composition analysis. The proposed method here predicts the molar distribution analysis of hydrocarbon in the plus fraction form above mention lab data. The resulting composition can then be used to predict the thermodynamics and phase behavior of HC systems by the EOSs.

The steps of the proposed method (4-Coefficient method) are:

1. Start with Ahmed proposed values for the four coefficients as in the following table:

Table 13: S Coefficient Values of 4-Coeffient Method.

\begin{tabular}{|c|c|c|}
\hline Coefficient (S) & No. of Carbon Atoms & S Coefficient Values \\
\hline 1 & $n=7$ & 15.5 \\
\hline 2 & $n=8$ & 15.5 \\
\hline 3 & $n=9$ & 17.0 \\
\hline 4 & $n \geq 10$ & 17.0 \\
\hline
\end{tabular}

2. Knowing the molecular weight of $\mathrm{C}_{7_{+}}$fraction $\left(\mathrm{MW}_{7_{+}}\right)$, Calculate the molecular weight of the octane plus fraction $\left(\mathrm{MW}_{8+}\right)$ by using the following equation:

$$
M_{(n+1)+}=M_{7+}+S(n-6)
$$

3. Calculate the mole fraction of the heptane fraction $\left(\mathrm{Z}_{7}\right)$ by using the following equation:

$$
z_{n}=z_{n+}\left[\frac{M_{(n+1)+}-M_{n+}}{M_{(n+1)+}-M_{n}}\right]
$$

Where:

$M_{n}=$ Molecular Weight of the $n$ fraction recommended by Katz-Firozabadi shown in the Generalized Physical Properties Table (APPENDIX II). 
4. Repeat steps 2 and 3 for each component in the system $\left(C 8, C_{9}, C_{10} \ldots . . C_{n}\right)$.

5. Calculate the average specific gravity for predicted molar distribution using the published values of molecular weights and specific gravities by Katz-Firozabadi (APPENDIX II). The average specific gravity for the predicted molar distribution is calculated as follows:

$$
\overline{S G_{C 7+}}=\frac{\sum_{i=7}^{n}\left(Z_{n} \times M W_{n} \times S G_{n}\right)}{Z_{C 7+} \times \overline{M W_{C 7+}}}
$$

Where:-

$S G_{n}=$ Specific Gravity of the $n$ fraction recommended by Katz-Firozabadi shown in the Generalized Physical Properties Table (APPENDIX II).

6. Determine the retrograde dew point pressure by using the predicted composition as input to the PC-version of the P-R-AGA program.

7. Compare the calculated average specific gravity of $\mathrm{C}_{\mathrm{n}+}$ and the determined retrograde dew point pressure with the reported values given in the HC Analysis and the $\mathrm{C}_{7+}$ properties. If the values not close enough (within $3 \%$ ), change the values of $S$ coefficients and repeat the steps 5 and 6 until get the best matching results.

To explain the methodology in detail, an example is shown and discussed in the following section. The data used is Pazanan Gas Condensate Sample from Iran. The results will be compared with the three previous methods that are applied.

\subsubsection{Splitting Sample of Pazanan Field by 4-Coefficient Method}

The published data of Pazanan gas condensate field, shown in Table 3, is used as an example to explain the 4-Coeffcient methodology. Samples from the Pazanan gas condensate reservoir were taken by the Core Laboratories, from the recombination of 
separator samples for experimental PVT measurements. The reservoir fluid was reported to at its dew point in the reservoir at pressure of 4076 psia and temperature of $180.5 \mathrm{deg}$ F and depth of $6700 \mathrm{ft}$.

The slops suggested by Ahmed are used as first attempt. These slopes are shown in Table 13 previously in step no. 1. They are used as a starting point in order to estimate the molar distribution, specific gravity and dew point pressure. The resulting compositional analysis for 30 components is shown in Table 14. The predicted specific gravity of the $\mathrm{C}_{7+}$ for this molar distribution was calculated to be 0.782 and the retrograde dew point pressure was predicted to be 4198 psia.

In order to get more matching between the predicted values and the reported values, the slopes have been changed. Also, the splitting has been performed for more than number of components. Table 15 summarized the distributed compositional analysis for $n=26$ with best results gained from changing the slops. The slopes that are used for this splitting are $S_{n=7}=11.4, S_{n=8}=14, S_{n=7}=16$ and $S_{n \geq 10}=17.7$. The results show that the new predicted specific gravity is 0.781 with difference less than $1 \%$. The predicted retrograde dew point pressure is 4076 psia with $0 \%$ difference. The compositional analysis for the sample with 30 components and 26 components is shown in the Figure 6.

The comparison between the proposed model and the existing splitting models is shown in Table 16. The results are presented in values comparing table and percentage comparing table. The splitting results are shown in Figure 7.

The 4-Coefficinet method is applied on a different gas condensate field's sample to validate its applicability and accuracy. In the following cases, the molar distribution obtained from the 4-Coefficient method and Ahmed Extend methods (the initial slops values) are compared. Also, their results are compared and shown in tables and figures. 
Table 14: The Compositional Analysis for $\mathrm{n}=30$ for Pazanan Sample using 4-Coefficient First attempt.

\begin{tabular}{|c|c|c|c|c|c|c|}
\hline \multirow{2}{*}{ SCN } & \multirow{2}{*}{ Mn } & \multirow{2}{*}{ SGn } & \multirow{2}{*}{ Mn+ } & \multirow{2}{*}{$\mathbf{z n}+$} & \multicolumn{2}{|c|}{ MOLE FRACTION } \\
\hline & & & & & 4-Coefficient & Experimental \\
\hline 7 & 96 & 0.727 & 132 & 3.1200 & 0.93903 & 0.75 \\
\hline 8 & 107 & 0.749 & 147.5 & 2.1810 & 0.60366 & 0.75 \\
\hline 9 & 121 & 0.768 & 163 & 1.5773 & 0.50881 & 0.49 \\
\hline 10 & 134 & 0.782 & 183 & 1.0685 & 0.27522 & 0.31 \\
\hline 11 & 147 & 0.793 & 200 & 0.7933 & 0.19265 & 0.22 \\
\hline 12 & 161 & 0.804 & 217 & 0.6006 & 0.13987 & 0.15 \\
\hline 13 & 175 & 0.815 & 234 & 0.4608 & 0.10306 & 0.12 \\
\hline 14 & 190 & 0.826 & 251 & 0.3577 & 0.07796 & 0.09 \\
\hline 15 & 206 & 0.836 & 268 & 0.2797 & 0.06020 & 0.07 \\
\hline 16 & 222 & 0.843 & 285 & 0.2195 & 0.04665 & 0.17 \\
\hline 17 & 237 & 0.851 & 302 & 0.1729 & 0.03584 & \\
\hline 18 & 251 & 0.856 & 319 & 0.1370 & 0.02741 & \\
\hline 19 & 263 & 0.861 & 336 & 0.1096 & 0.02071 & \\
\hline 20 & 275 & 0.866 & 353 & 0.0889 & 0.01591 & \\
\hline 21 & 291 & 0.871 & 370 & 0.0730 & 0.01293 & \\
\hline 22 & 300 & 0.876 & 387 & 0.0601 & 0.00982 & \\
\hline 23 & 312 & 0.881 & 404 & 0.0503 & 0.00784 & \\
\hline 24 & 324 & 0.885 & 421 & 0.0424 & 0.00633 & \\
\hline 25 & 337 & 0.888 & 438 & 0.0361 & 0.00520 & \\
\hline 26 & 349 & 0.892 & 455 & 0.0309 & 0.00427 & \\
\hline 27 & 360 & 0.896 & 472 & 0.0266 & 0.00351 & \\
\hline 28 & 372 & 0.899 & 489 & 0.0231 & 0.00293 & \\
\hline 29 & 382 & 0.902 & 506 & 0.0202 & 0.00243 & \\
\hline 30 & 394 & 0.905 & 523 & 0.0178 & 0.01775 & \\
\hline
\end{tabular}

\begin{tabular}{|l|c|}
\hline \multicolumn{1}{|c|}{ SCN } & S Values \\
\hline$n=7$ & 15.5 \\
\hline$n=8$ & 15.5 \\
\hline$n=9$ & 17 \\
\hline$n>10$ & 17 \\
\hline
\end{tabular}

\begin{tabular}{|l|r|r|}
\hline \multicolumn{1}{|c|}{ C7+ Properties: } & \multicolumn{1}{c|}{ Results } & \multicolumn{1}{c|}{$\%$} \\
\hline ZnC7+ $=$ & 3.12 & 0.00 \\
\hline MWC7+ $=$ & 131 & -0.56 \\
\hline SGC7+ = & 0.782 & 1.02 \\
\hline Dew Point Pressure $=$ & 4198 & 2.99 \\
\hline
\end{tabular}


Table 15: The Compositional Analysis for $n=26$ for Pazanan Sample using 4-Coefficient First attempt.

\begin{tabular}{|c|c|c|c|c|c|c|}
\hline \multirow{2}{*}{ SCN } & \multirow{2}{*}{ Mn } & \multirow{2}{*}{ SGn } & \multirow{2}{*}{ Mn+ } & \multirow{2}{*}{ zn+ } & \multicolumn{2}{|c|}{ MOLE FRACTION } \\
\cline { 6 - 7 } & & & & 4-coefficient & Experimental \\
\hline 7 & 96 & 0.727 & 132 & 3.1200 & 0.75038 & 0.75 \\
\hline 8 & 107 & 0.749 & 143.4 & 2.3696 & 0.74218 & 0.75 \\
\hline 9 & 121 & 0.768 & 160 & 1.6274 & 0.55167 & 0.49 \\
\hline 10 & 134 & 0.782 & 180 & 1.0758 & 0.35650 & 0.31 \\
\hline 11 & 147 & 0.793 & 202.8 & 0.7193 & 0.17321 & 0.22 \\
\hline 12 & 161 & 0.804 & 220.5 & 0.5461 & 0.12520 & 0.15 \\
\hline 13 & 175 & 0.815 & 238.2 & 0.4209 & 0.09208 & 0.12 \\
\hline 14 & 190 & 0.826 & 255.9 & 0.3288 & 0.06961 & 0.09 \\
\hline 15 & 206 & 0.836 & 273.6 & 0.2592 & 0.05378 & 0.07 \\
\hline 16 & 222 & 0.843 & 291.3 & 0.2054 & 0.04179 & 0.17 \\
\hline 17 & 237 & 0.851 & 309 & 0.1636 & 0.03228 & \\
\hline 18 & 251 & 0.856 & 326.7 & 0.1313 & 0.02489 & \\
\hline 19 & 263 & 0.861 & 344.4 & 0.1064 & 0.01901 & \\
\hline 20 & 275 & 0.866 & 362.1 & 0.0874 & 0.01477 & \\
\hline 21 & 291 & 0.871 & 379.8 & 0.0727 & 0.01208 & \\
\hline 22 & 300 & 0.876 & 397.5 & 0.0606 & 0.00931 & \\
\hline 23 & 312 & 0.881 & 415.2 & 0.0513 & 0.00751 & \\
\hline 24 & 324 & 0.885 & 432.9 & 0.0438 & 0.00612 & \\
\hline 25 & 337 & 0.888 & 450.6 & 0.0376 & 0.00508 & \\
\hline 26 & 349 & 0.892 & 468.3 & 0.0326 & 0.03257 & \\
\hline & & & & & & \\
\hline
\end{tabular}

\begin{tabular}{|l|c|}
\hline \multicolumn{1}{|c|}{ SCN } & S Values \\
\hline$n=7$ & 11.4 \\
\hline$n=8$ & 14 \\
\hline$n=9$ & 16 \\
\hline$n>10$ & 17.7 \\
\hline
\end{tabular}

\begin{tabular}{|l|r|r|}
\hline \multicolumn{1}{|c|}{ C7+ Properties: } & \multicolumn{1}{c|}{ Results } & \multicolumn{1}{c|}{$\%$} \\
\hline ZnC7 $+=$ & 3.12 & 0.00 \\
\hline MWC7+ $=$ & 131 & -0.94 \\
\hline SGC7 $+=$ & 0.781 & 0.92 \\
\hline Dew Point Pressure $=$ & 4076 & 0.01 \\
\hline
\end{tabular}




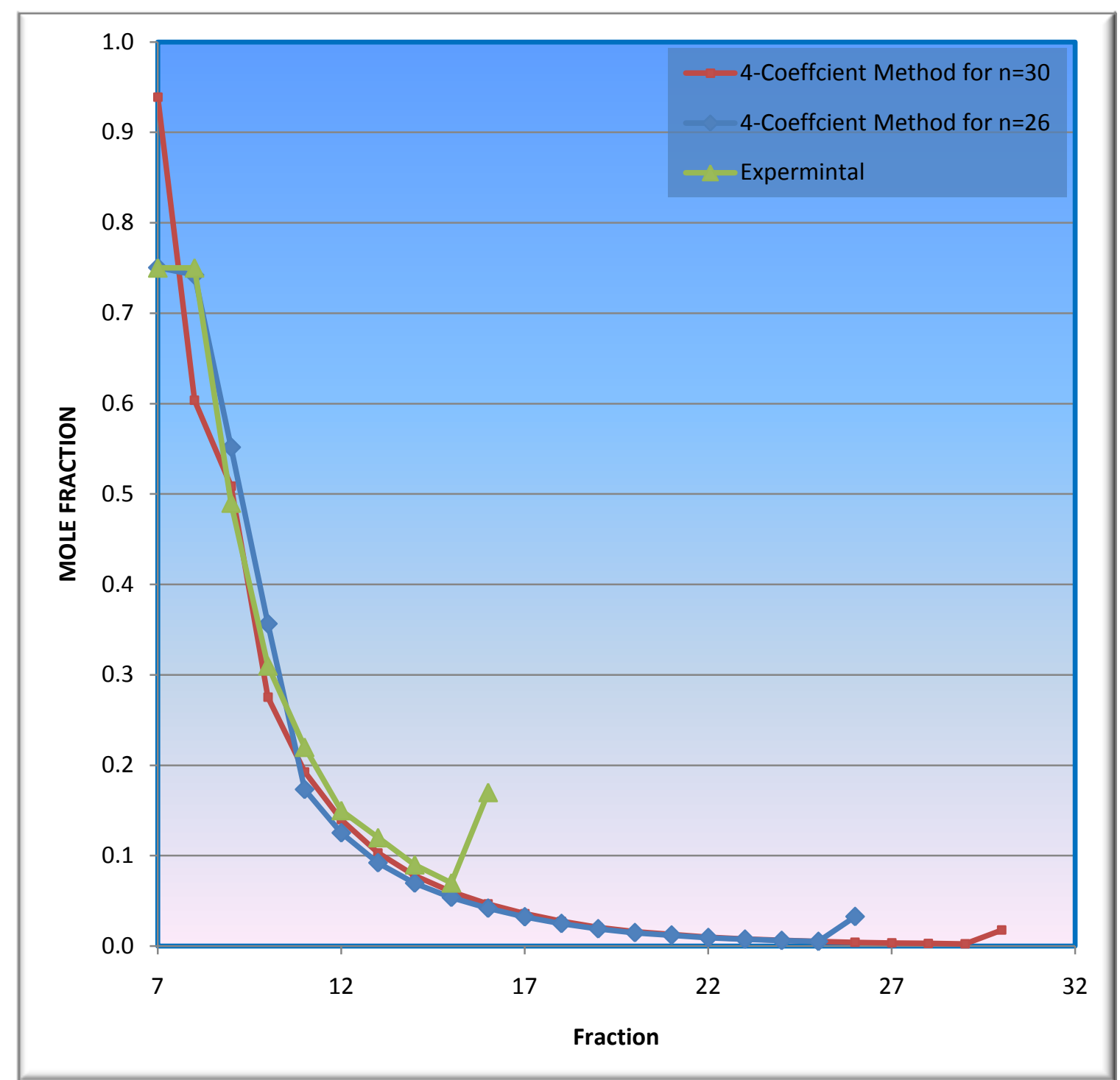

Figure 6: The compositional analysis for the sample with 30 and 26 component.

Table 16: The Comparison of the Splitting methods with the proposed Methodology.

\begin{tabular}{|c|c|c|c|c|c|}
\hline \multirow[b]{2}{*}{ C7+ Properties } & \multirow{2}{*}{$\begin{array}{c}\text { Lab } \\
\text { Reported } \\
\text { Results }\end{array}$} & \multicolumn{4}{|c|}{ The Splitting Methods } \\
\hline & & $\begin{array}{c}\text { Katz } \\
\text { Method }\end{array}$ & $\begin{array}{l}\text { Ahmed } \\
\text { Method }\end{array}$ & $\begin{array}{l}\text { Marching } \\
\text { Technique }\end{array}$ & $\begin{array}{l}\text { 4-Coeffcient } \\
\text { Method }\end{array}$ \\
\hline Mole Fraction & 3.12 & 3.12 & 3.12 & 3.12 & 3.12 \\
\hline Molecular Weight & 132 & 144 & 131 & 132 & 131 \\
\hline Specific Gravity & 0.774 & 0.685 & 0.782 & 0.782 & 0.781 \\
\hline Retrograde D. P. P. & 4076 & 4656 & 4198 & 4228 & 4076 \\
\hline
\end{tabular}

\begin{tabular}{|l|c|c|c|c|c|}
\hline \multicolumn{5}{|c|}{ \% Difference } \\
\hline Mole Fraction & & & & & \\
\hline Molecular Weight & & 8.71 & -0.56 & -0.05 & -0.94 \\
\hline Specific Gravity & & -11.44 & 1.02 & 1.08 & 0.92 \\
\hline Retrograde D. P. P. & & 14.23 & 2.99 & 3.73 & 0.01 \\
\hline
\end{tabular}




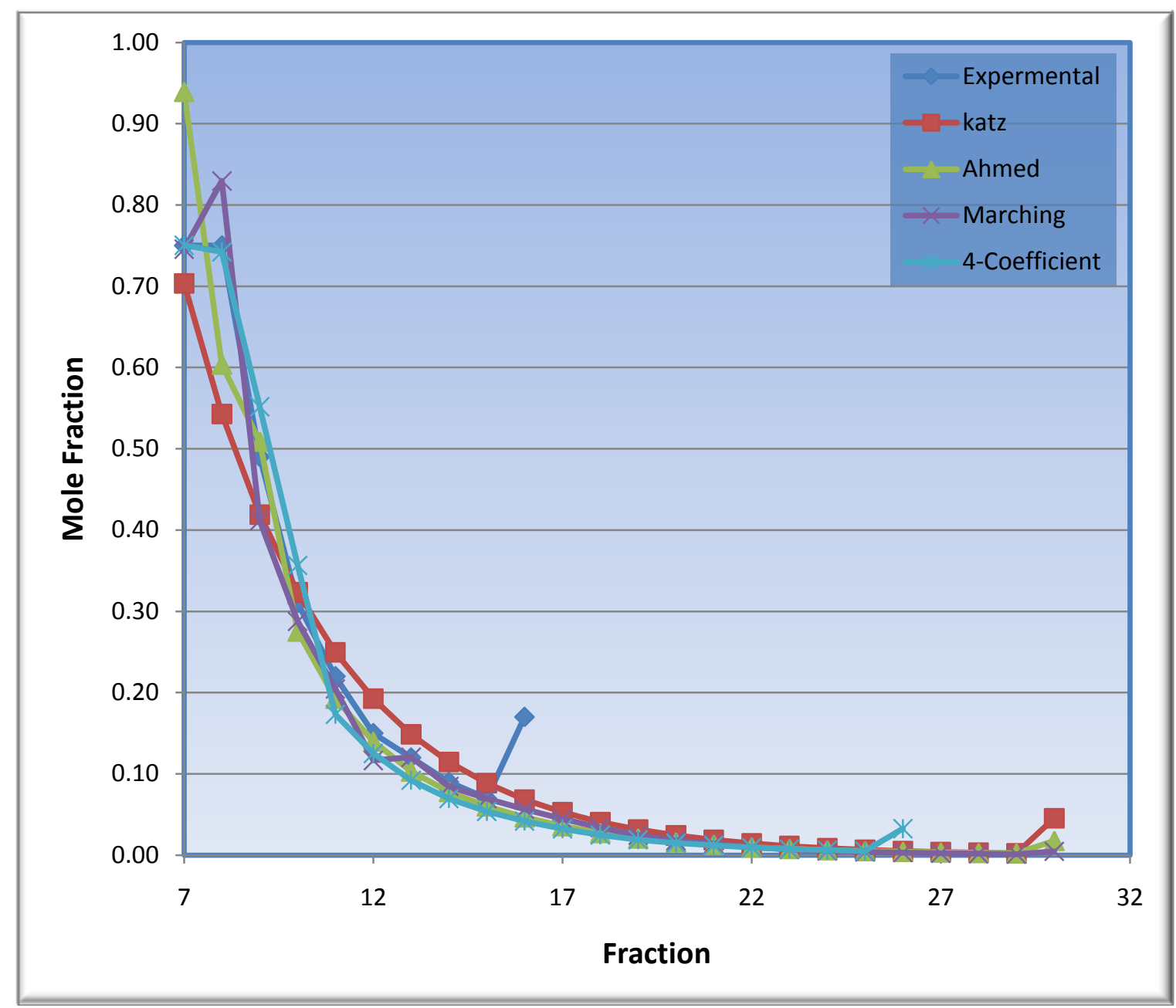

Figure 7: Comparison of Various Splitting Scheme Results with the 4-Coefficient Result for Pazanan Field Data.

\subsection{Verification}

\subsubsection{Rapid River 35 Field}

The Rapid River 35 is a gas condensate reservoir in Niagran-pinnacle reef in north of Michigan State. Its initial reservoir pressure was 3485 psia with temperature of 114 deg F. The reservoir dew point pressure was 3309 psia. The $\mathrm{C}_{7+}$ mole fraction was 1.83 . The molecular weight and the specific gravity were 129 and 0.773 , consequentially. The molar distribution of the heptane plus was predicted using 4-Coefficient method for different number of components. The best splitting results are gained with 25 fractions and 15 fractions. These results are reported and compared with lab experimental and initial slops extended scheme. 


\subsubsection{Cold spring 12 Field}

The Cold Spring 12 is a gas condensate reservoir in a Niagran-pinnacle reef in north of Michigan State. It had an initial reservoir pressure of 3453 psia and a reservoir temperature of $114 \mathrm{deg}$ F. The measured reservoir dew point pressure was $3620 \mathrm{psia}$. The $\mathrm{C}_{7+}$ mole fraction was 2.83 . The heptane plus fraction had an average molecular weight of 125 and a specific gravity of 0.773 . The molar distribution of the heptane plus was predicted using the 4-Coeffcient method for different number of components. The best results of number of components are $(n=30)$ and $(n=23)$.

\subsubsection{Chester 15 Field}

The Chester 15 is a gas condensate reservoir in a Niagran-pinnacle reef in north of Michigan State. It had an initial reservoir pressure of 3103 psia and a reservoir temperature of $113 \mathrm{deg}$ F. The measured reservoir dew point pressure was $2668 \mathrm{psia}$. The $\mathrm{C}_{7+}$ mole fraction was 1.94 . The heptane plus fraction had an average molecular weight of 123 and a specific gravity of 0.756 . The molar distribution of the heptane plus was predicted using the 4-Coeffcient method for different number of components. It was difficult to get good results. It was needed to lower the number of components to 12 components or even less to come closer to the reported data.

\subsubsection{Khuff 4 Field}

The Khuff 4 is an offshore gas condensate reservoir in north field of Khuff reservoir on the northwest tip of Qatar. Constant volume depletion at $220 \mathrm{deg} F$ gave a retrograde dew point pressure of 5120 psia. The $\mathrm{C}_{7+}$ mole fraction was 2.15 . The heptane plus fraction had an average molecular weight of 135 (estimated) and a specific gravity of 0.76 . The molar distribution of the heptane plus was predicted using the 4-Coeffcient method for different number of components. The best results of number of components $(n=30)$ are reported and compared with other compositional analysis. The adjustment of heavy fractions critical properties such as temperature, pressure and acentric factor can reduce 
the dissimilarities between the predicted and measured dew point pressure. In considering to this fact, the critical properties of the heptane plus were increased by $0.08 \%$

\subsubsection{Dakhni Field}

The Dakhni field is a gas condensate reservoir in the Potwar Region basin in northern side of Pakistan. The reported well stream analysis displayed an unusual behavior for this condensate. The reservoir temperature estimated to be $220 \mathrm{deg} F$ (Calculated from Temperature-Depth relation) and a retrograde dew point pressure of 5668 psia. The $\mathrm{C}_{7+}$ mole fraction was 1.3. The heptane plus fraction had an average molecular weight of 136 (estimated) and a specific gravity of 0.796. The molar distribution of the heptane plus was predicted using the 4-Coeffcient method for different number of components. In order to reduce the dissimilarities between the predicted and measured dew point pressure, it was necessary to adjust critical properties for heavy fractions such as temperature, pressure and acentric factor which were decreased by $60 \%$ for this case.

Moreover, the gas reservoir depletion analysis was performed to evaluate the accuracy of the 4-Coeffcient method as compare to the existing methods. The depletion calculations provide the constant volume depletion (CVD) result at series of pre-specified pressures at reservoir temperature. The outlet provides the composition of produced gas, the percentage of reservoir gas produced, the liquid volume percentage, the two phase compressibility factor, the molecular weights of heptane plus and the specific gravity of heptane plus. The calculated properties from the extended calculations were also used to aid in the comparison.

To evaluate the accuracy of the results, the laboratory determined extended composition was used with Phase Behavior Package to run similar CVD. The result of this run was used as the basis for comparing various methods. These comparisons are presented as absolute percentages of differences and then they are averaged in order to check its result against the Extended Composition CVD composition result. 
Figure 8 and Table 17 summarize the results of the comparison among various techniques and Extended Composition CVD results for fraction of Heptane plus in the produced well stream. As it can be seen, the 4-Coefficient method results are closest to Extended Composition CVD results.

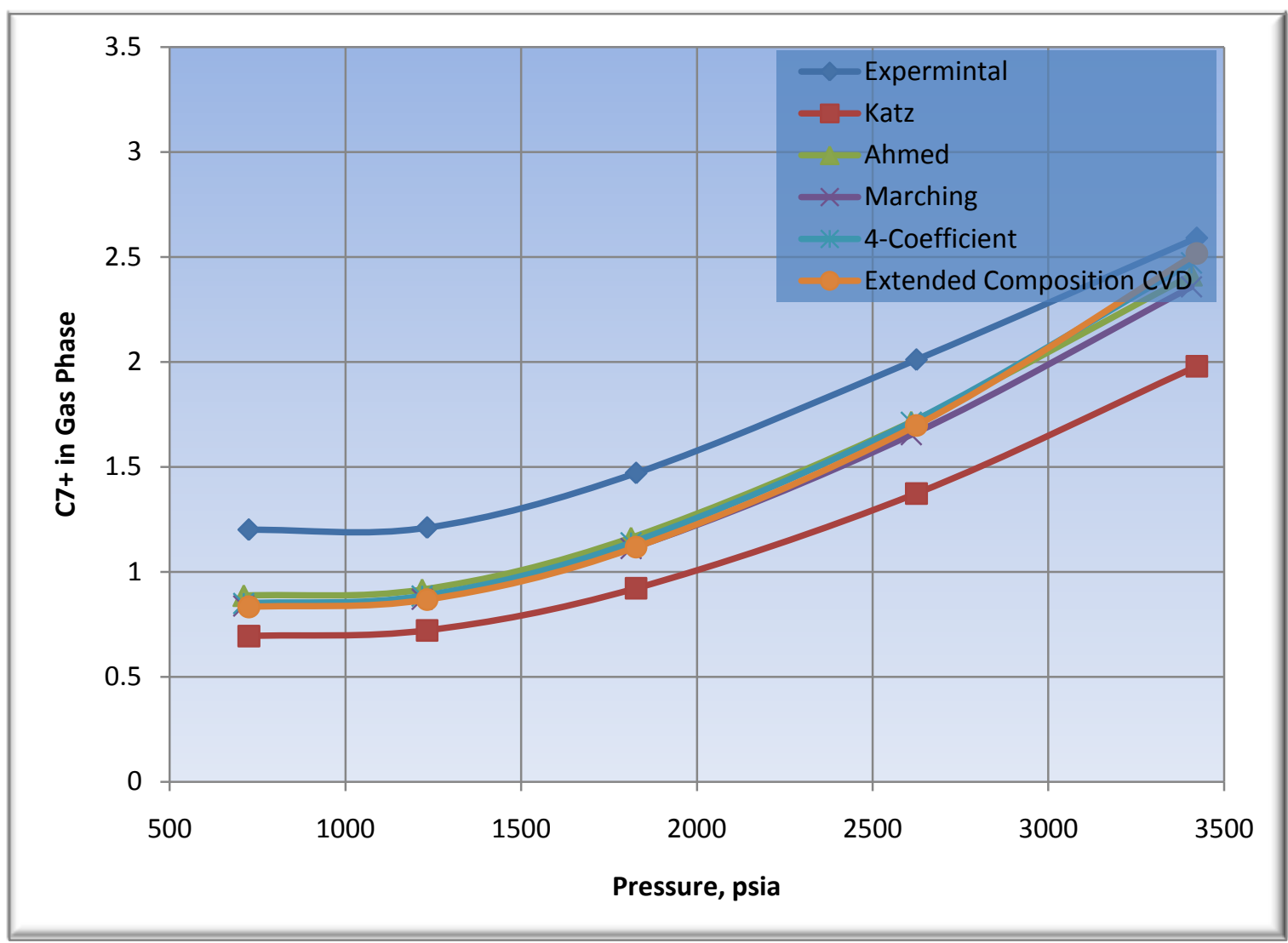

Figure 8: Comparison of the Heptane plus in Gas Phase.

For the percentage of the produced well stream, the 4-Coefficient method is shown the least deviation as compare to Extended Composition CVD results. These results are shown in Figure 9 and Table 17.

In comparing the Volume \% liquid with the Extended Composition CVD results, the 4Coeffcient method is giving the least difference among all splitting methods with $8 \%$. The results are drawn in Figure 10 and presented in Table 17. 


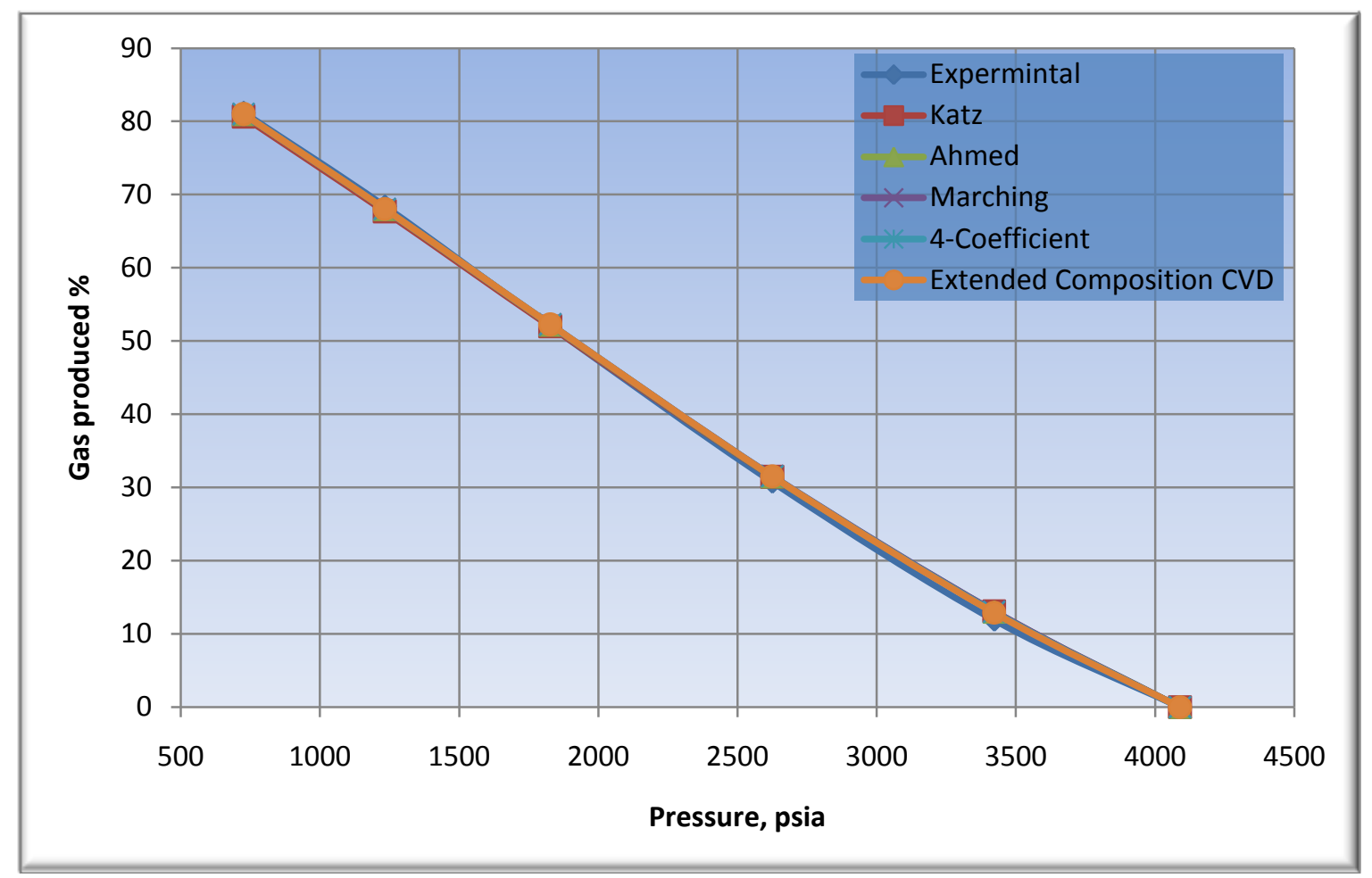

Figure 9: Comparison of the Well Stream Produced.

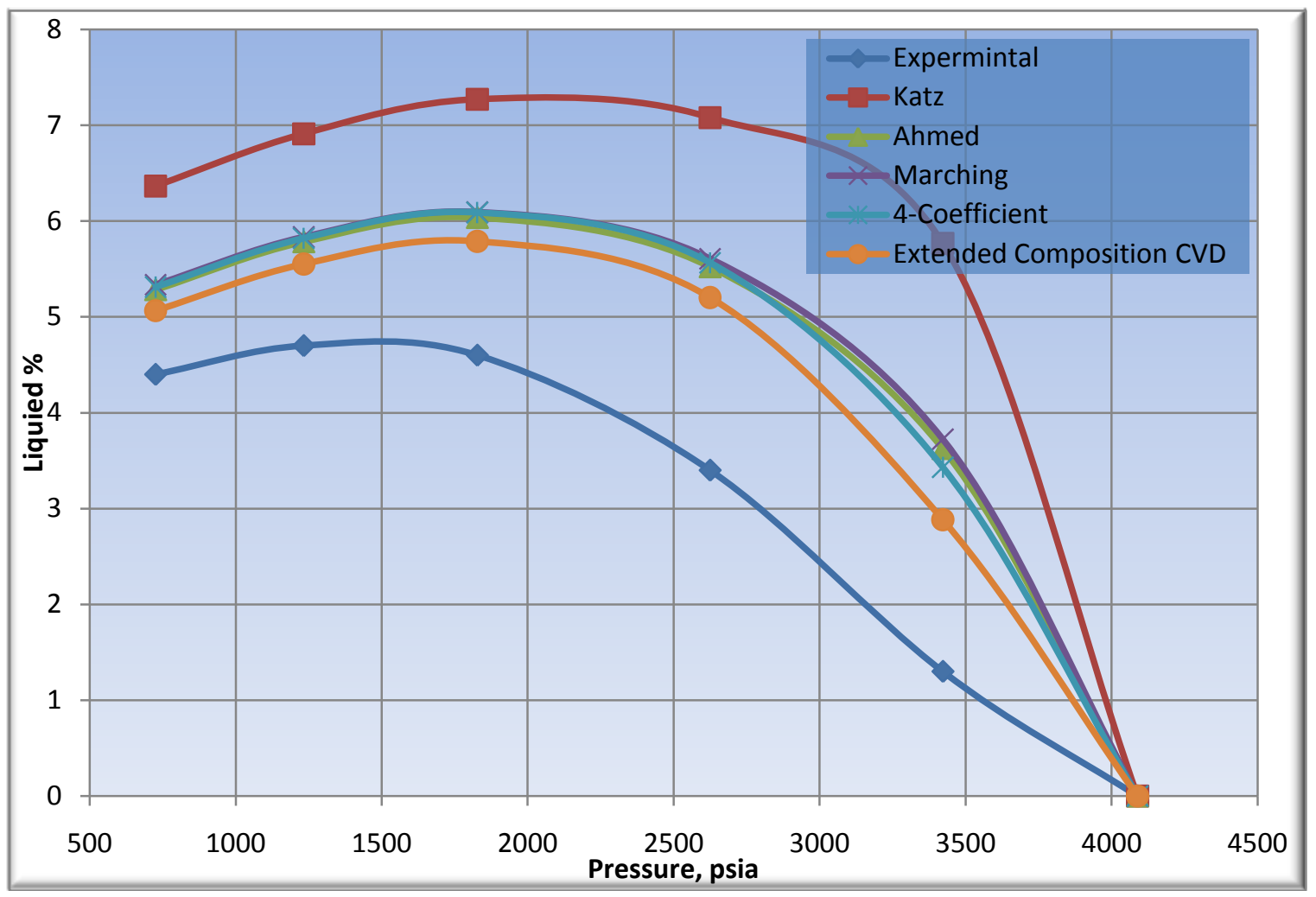

Figure 10: Comparison of the Volume \% Liquid. 
The calculated 2-phase Gas Compressibility Factor ( $\mathrm{Z})$ is presented in Table 17. All the methods are shown close values to the Extended Composition CVD results but the 4Coeffecient is giving the least difference as it can be seen in Figure 11.

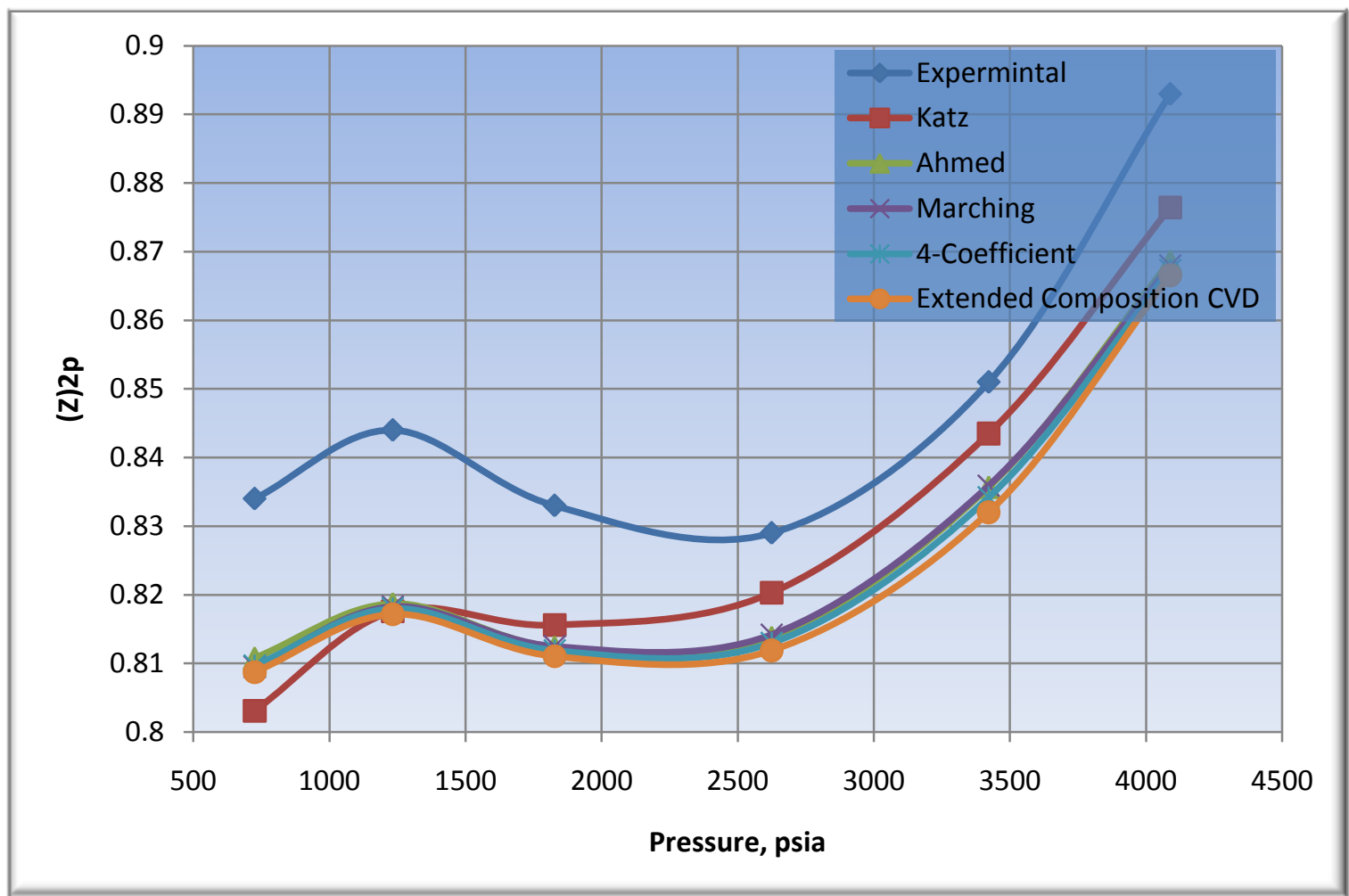

Figure 11: Comparison of the Compressibility Factor of Gas (Z) 2p.

The same conclusion was also reached for the heptane plus molecular weight and specific gravity when comparing the 4-Coeffecint method and the splitting methods with the Extended Composition CVD results as illustrated in Figure 12, Figure 13 and summarized in Table 17.

For the calculated properties from the extended composition, the 4-Coeffcient is presenting the least average difference from the Extended Composition CVD results with only $0.42 \%$. The calculated properties and the comparisons are presented in Table 17. 


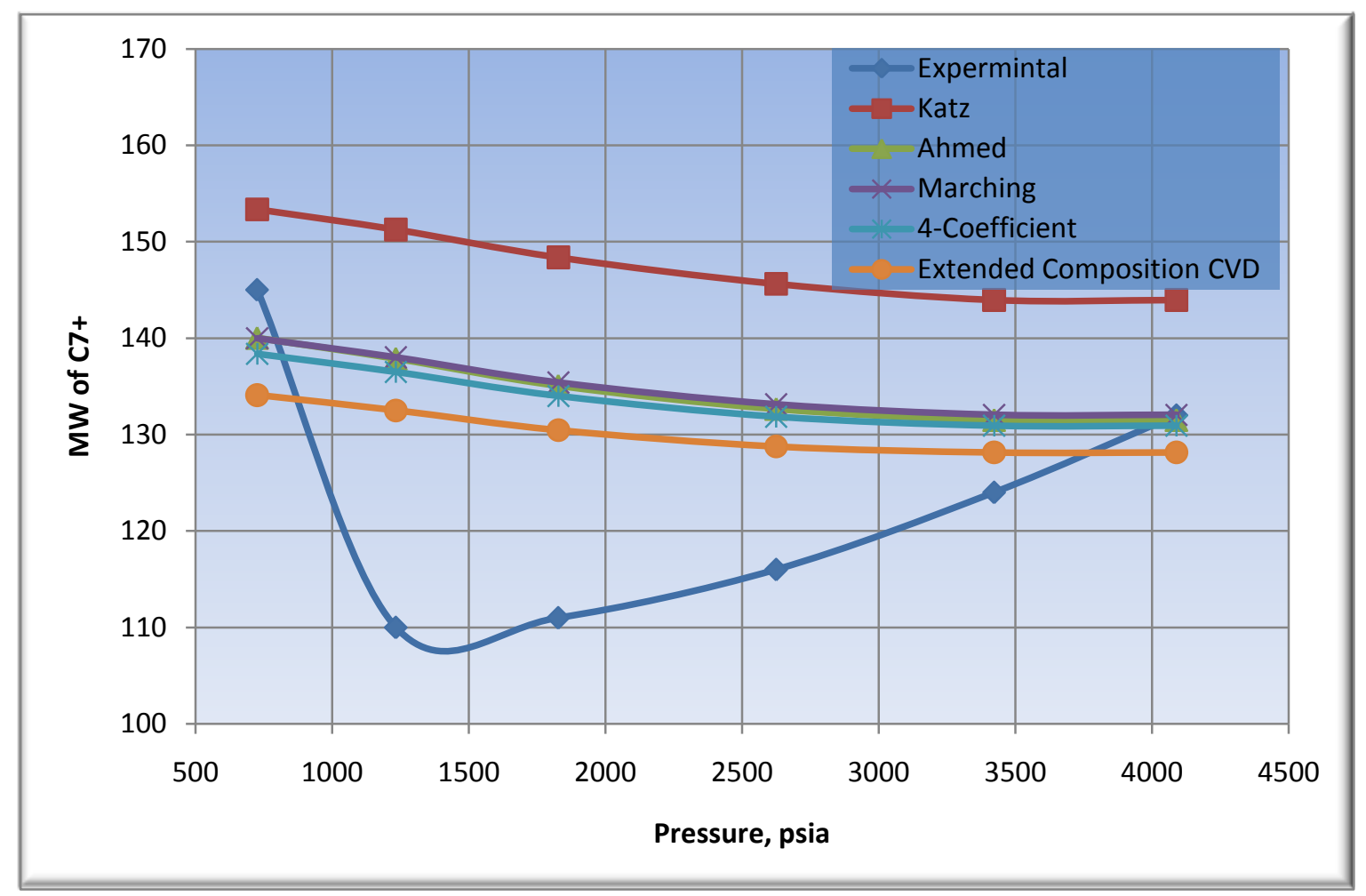

Figure 12: Comparison of the Molecular Weight of the Heptane plus.

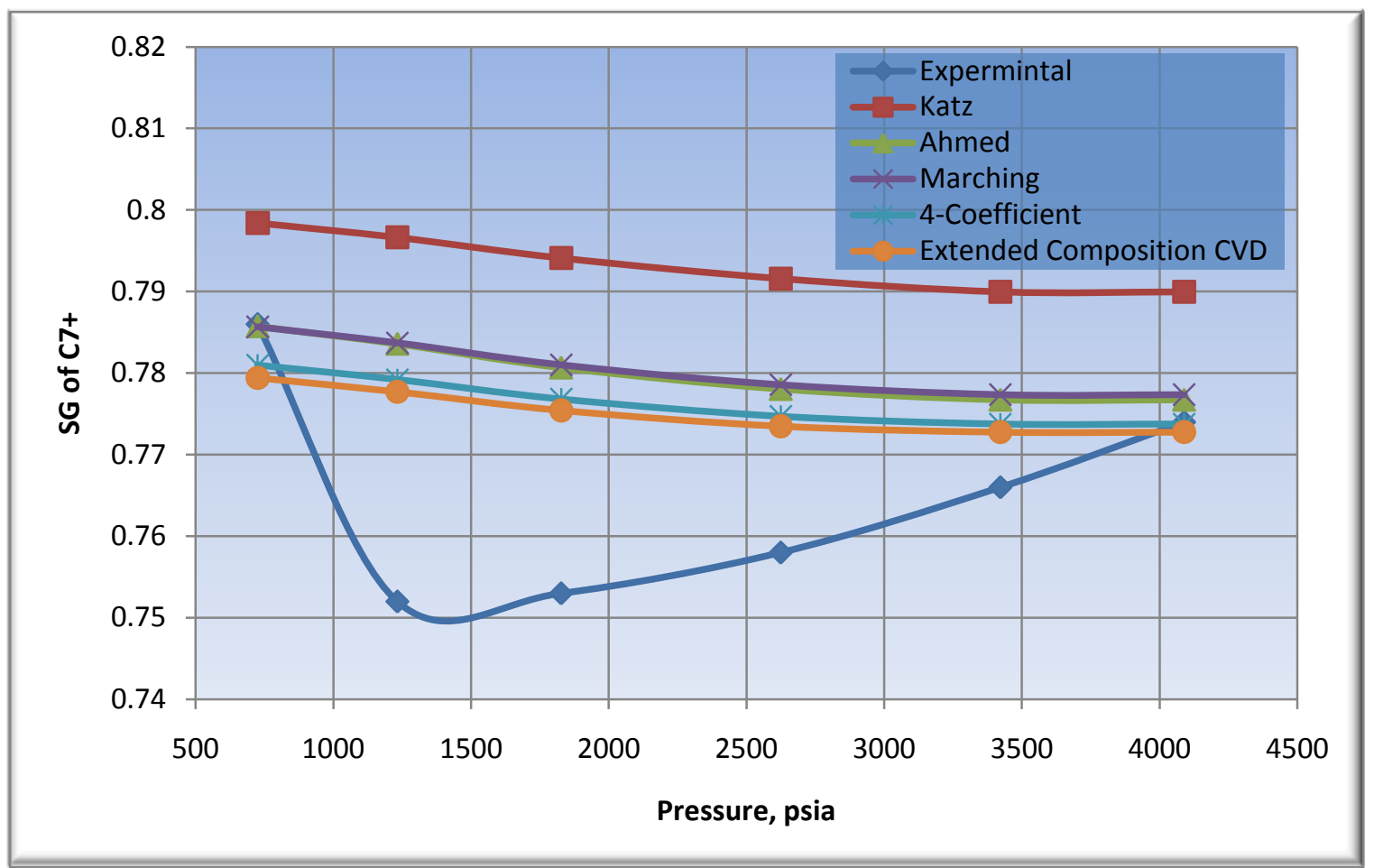

Figure 13: Comparison of the Specific Gravity of Heptane plus. 
Table 17: The Summary of Gas Deplition Calculations and the Absulute Differnce Percentages.

\begin{tabular}{|c|c|c|c|c|c|c|c|c|c|c|c|}
\hline \multirow{2}{*}{ Property } & \multirow{2}{*}{$\begin{array}{l}\text { Pressure } \\
\text { Psia }\end{array}$} & \multirow[b]{2}{*}{ Experiment } & \multirow[b]{2}{*}{ Katz } & \multirow[b]{2}{*}{ Ahmed } & \multirow[b]{2}{*}{ Marching } & \multirow[b]{2}{*}{ 4-Coefficient } & \multirow[b]{2}{*}{ Actual } & \multicolumn{4}{|c|}{ ABS percentage difference } \\
\hline & & & & & & & & Katz & Ahmed & Marching & 4-Coefficient \\
\hline \multirow{6}{*}{ 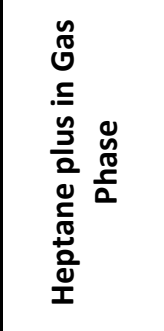 } & 3422.2 & 2.59 & 1.97869 & 2.41306 & 2.35712 & 2.47132 & 2.51561 & 21.34 & 4.08 & 6.3 & 1.76 \\
\hline & 2624.7 & 2.01 & 1.37295 & 1.71354 & 1.65239 & 1.71239 & 1.69673 & 19.08 & 0.99 & 2.61 & 0.92 \\
\hline & 1827.2 & 1.47 & 0.9211 & 1.16148 & 1.1105 & 1.13742 & 1.11748 & 17.57 & 3.94 & 0.62 & 1.78 \\
\hline & 1232.7 & 1.21 & 0.72089 & 0.91476 & 0.86885 & 0.88424 & 0.86751 & 16.9 & 5.45 & 0.15 & 1.93 \\
\hline & 725.2 & 1.2 & 0.69374 & 0.88647 & 0.83751 & 0.84931 & 0.83262 & 16.68 & 6.47 & 0.59 & 2 \\
\hline & & & & & & & Average $=$ & 18.32 & 4.18 & 2.06 & 1.68 \\
\hline \multirow{7}{*}{ 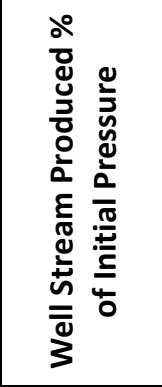 } & 4089.2 & 0 & 0 & 0 & 0 & 0 & 0 & & & & \\
\hline & 3422.2 & 11.911 & 13.09 & 13.014 & 13.101 & 12.989 & 12.888 & 1.57 & 0.98 & 1.65 & 0.78 \\
\hline & 2624.7 & 30.766 & 31.456 & 31.491 & 31.577 & 31.531 & 31.531 & 0.24 & 0.13 & 0.15 & 0 \\
\hline & 1827.2 & 52.054 & 52.006 & 52.227 & 52.269 & 52.269 & 52.285 & 0.53 & 0.11 & 0.03 & 0.03 \\
\hline & 1232.7 & 68.406 & 67.704 & 68.018 & 68.026 & 68.041 & 68.051 & 0.51 & 0.05 & 0.04 & 0.01 \\
\hline & 725.2 & 81.205 & 80.657 & 81.003 & 80.987 & 81.006 & 81.009 & 0.43 & 0.01 & 0.03 & 0 \\
\hline & & & & & & & Average $=$ & 0.66 & 0.25 & 0.38 & 0.17 \\
\hline \multirow{7}{*}{ 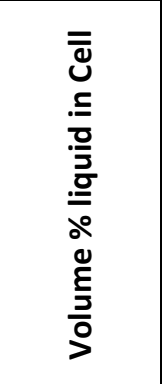 } & 4089.2 & 0 & 0 & 0 & 0 & 0 & 0 & & & & \\
\hline & 3422.2 & 1.3 & 5.7678 & 3.6251 & 3.7228 & 3.4312 & 2.8838 & 100.01 & 25.71 & 29.09 & 18.98 \\
\hline & 2624.7 & 3.4 & 7.0789 & 5.5223 & 5.6071 & 5.5649 & 5.2023 & 36.07 & 6.15 & 7.78 & 6.97 \\
\hline & 1827.2 & 4.6 & 7.2702 & 6.0363 & 6.0932 & 6.0884 & 5.788 & 25.61 & 4.29 & 5.27 & 5.19 \\
\hline & 1232.7 & 4.7 & 6.9103 & 5.7834 & 5.8337 & 5.8205 & 5.5511 & 24.49 & 4.18 & 5.09 & 4.85 \\
\hline & 725.2 & 4.4 & 6.3657 & 5.2832 & 5.3345 & 5.3108 & 5.0653 & 25.67 & 4.3 & 5.31 & 4.85 \\
\hline & & & & & & & Average $=$ & 42.37 & 8.93 & 10.51 & 8.17 \\
\hline \multirow{3}{*}{ 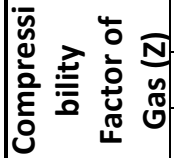 } & 4089.2 & 0.893 & 0.87643 & 0.8686 & 0.867973 & 0.86732 & 0.86656 & 1.14 & 0.24 & 0.16 & 0.09 \\
\hline & 3422.2 & 0.851 & 0.8435 & 0.8357 & 0.8359 & 0.8342 & 0.832023 & 1.38 & 0.44 & 0.47 & 0.26 \\
\hline & 2624.7 & 0.829 & 0.8203 & 0.8138 & 0.8142 & 0.813 & 0.811885 & 1.04 & 0.24 & 0.29 & 0.14 \\
\hline
\end{tabular}




\begin{tabular}{|c|c|c|c|c|c|c|c|c|c|c|c|}
\hline & 1827.2 & 0.833 & 0.8156 & 0.8124 & 0.8125 & 0.8119 & 0.811036 & 0.56 & 0.17 & 0.18 & 0.11 \\
\hline & 1232.7 & 0.844 & 0.8176 & 0.8187 & 0.8183 & 0.818 & 0.817153 & 0.05 & 0.19 & 0.14 & 0.1 \\
\hline & 725.2 & 0.834 & 0.8031 & 0.8108 & 0.8095 & 0.8097 & 0.808734 & 0.7 & 0.26 & 0.09 & 0.12 \\
\hline & & & & & & & Average $=$ & 0.81 & 0.26 & 0.22 & 0.14 \\
\hline \multirow{7}{*}{ 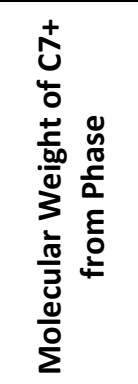 } & 4089.2 & 132 & 143.9611 & 131.5018 & 132.0448 & 130.916715 & 128.1509 & 12.34 & 2.61 & 3.04 & 2.16 \\
\hline & 3422.2 & 124 & 143.9611 & 131.5018 & 132.0448 & 130.916715 & 128.1509 & 12.34 & 2.61 & 3.04 & 2.16 \\
\hline & 2624.7 & 116 & 145.6302 & 132.6509 & 133.1274 & 131.8521675 & 128.7667 & 13.1 & 3.02 & 3.39 & 2.4 \\
\hline & 1827.2 & 111 & 148.3729 & 135.056 & 135.3974 & 134.0069328 & 130.4535 & 13.74 & 3.53 & 3.79 & 2.72 \\
\hline & 1232.7 & 110 & 151.259 & 137.8627 & 138.0088 & 136.494706 & 132.5088 & 14.15 & 4.04 & 4.15 & 3.01 \\
\hline & 725.2 & 145 & 153.3544 & 140.0122 & 139.9844 & 138.3778542 & 134.0931 & 14.36 & 4.41 & 4.39 & 3.2 \\
\hline & & & & & & & Average $=$ & 13.34 & 3.37 & 3.63 & 2.61 \\
\hline \multirow{7}{*}{ 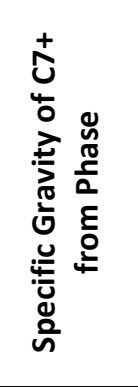 } & 4089.2 & 0.774 & 0.789966 & 0.776726 & 0.777353 & 0.773732201 & 0.772755 & 2.23 & 0.51 & 0.6 & 0.13 \\
\hline & 3422.2 & 0.766 & 0.789966 & 0.776726 & 0.777353 & 0.773732201 & 0.772755 & 2.23 & 0.51 & 0.6 & 0.13 \\
\hline & 2624.7 & 0.758 & 0.791586 & 0.778043 & 0.778565 & 0.774670971 & 0.773479 & 2.34 & 0.59 & 0.66 & 0.15 \\
\hline & 1827.2 & 0.753 & 0.794109 & 0.780664 & 0.781002 & 0.776792921 & 0.775411 & 2.41 & 0.68 & 0.72 & 0.18 \\
\hline & 1232.7 & 0.752 & 0.796639 & 0.783585 & 0.78369 & 0.779186886 & 0.777688 & 2.44 & 0.76 & 0.77 & 0.19 \\
\hline & 725.2 & 0.786 & 0.79841 & 0.785738 & 0.785654 & 0.780953174 & 0.779393 & 2.44 & 0.81 & 0.8 & 0.2 \\
\hline & & & & & & & Average $=$ & 2.35 & 0.64 & 0.69 & 0.16 \\
\hline \multirow{5}{*}{ 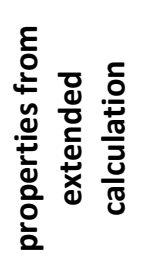 } & $\mathrm{ZnC7}+=$ & 3.12 & 3.12 & 3.12 & 3.1 & 3.12 & & 0 & 0 & 0.64 & 0 \\
\hline & $\mathrm{MW}=$ & 132 & 144 & 131 & 131.9 & 131 & & 8.71 & 0.56 & 0.05 & 0.94 \\
\hline & $S G=$ & 0.774 & 0.685 & 0.782 & 0.782 & 0.781 & & 11.44 & 1.02 & 1.08 & 0.92 \\
\hline & Dew $P=$ & 4076 & 4656 & 4197.99 & 4227.89 & 4076.44 & & 14.23 & 2.99 & 3.73 & 0.01 \\
\hline & & & & & & & Average $=$ & 8.6 & 1.14 & 1.37 & 0.47 \\
\hline
\end{tabular}




\section{CHAPTER 4: THE RESULTS \& DISCUSSIONS}

This section summarizes the result of predicting the extended compositions of gas condensate fluid for the studied fields' samples. The results include a comparison of the extended samples mole fractions, extended heptane plus specific gravity and retrograde dew point pressure. The extended compositions using 4-coefficient method are shown with the help of plots and tables for each sample.

\subsection{Rapid River 35 Field}

Splitting by using the suggested Ahmed's slops results in specific gravity of 0.778 with $1.1 \%$ difference and retrograde dew point pressure of 3647 psia with $10 \%$ difference. However, the calculated specific gravity was 0.774 and the retrograde dew point pressure was 3329 psia for splitting by 4-Coefficient method with 24 components. Also, the specific gravity was 0.772 and the retrograde dew point pressure was 3310 psia for splitting by the proposed method with 15 components. The percentage difference for this method is much less than $1 \%$. These results prove that the 4-Coeffcient methodology can further predict the molar distribution of the heptane plus accurately. These results are summarized in Table 18 and presented in Figure 14.

\subsection{Cold spring 12 Field}

The initial splitting of predicted molar distribution for $\mathrm{C}_{7+}$ resulted in a specific gravity of 0.774 with $0.08 \%$ difference and a retrograde dew point pressure of 3649 psia with 0.81

$\%$ difference. However, the calculated specific gravity was 0.773 and the retrograde dew point pressure was 3613 psia for splitting by 4-Coeffcient $(n=30)$ components. Also, the specific gravity was 0.773 and the retrograde dew point pressure was 3620 psia for splitting by the proposed method with 23 components. Almost there are no differences for this case. The 4-Coeffcient methodology compositions and results with comparing to the lab and initial extension are presented in Figure 15 and summarized in Table 19. 


\subsection{Chester 15 Field}

The predicted molar distribution for $\mathrm{C}_{7+}$ initially resulted in a specific gravity of 0.771 with $1.99 \%$ difference and a retrograde dew point pressure of 3153 psia with $18.16 \%$ difference. However, the calculated specific gravity was 0.762 and the retrograde dew point pressure was 2810 psia for splitting by 4-Coeffcient method with 12 components. Also, the specific gravity was 0.758 and the retrograde dew point pressure was 2709 psia for splitting by the proposed method with only 11 components. The compositions, results and the comparison are presented in Figure 16 and Table 20.

\subsection{Khuff 4 Field}

The molar distribution for $\mathrm{C}_{7+}$ of the Khuff 4 was predicted using initial slops and the results were specific gravity of 0.786 with $3.38 \%$ difference and a retrograde dew point pressure of 4260 psia with $-16.80 \%$ differences. However, the calculated specific gravity was 0.786 (3.43\% difference) and the retrograde dew point pressure was 4976 psia ($2.82 \%$ difference) for splitting by 4-Coeffcient method with 30 components. Increasing these properties by $0.08 \%$ was in a dew point pressure of 5112 psia which is much closer to the reported value. The 4-Coeffcient method compositions, results and comparison are presented in Figure 17. The results are summarized in Table 21.

\subsection{Dakhni Field}

The prediction of molar distribution for $C_{7+}$ initially resulted in a specific gravity of 0.787 $(-1.13 \%)$ and a retrograde dew point pressure of 5342 psia $(-5.74 \%)$. However, the calculated specific gravity was 0.784 (-1.5\% difference) and the retrograde dew point pressure was 5430 psia (-4.2\% difference) for splitting by 4-Coeffcient method with 25 components. It was necessary to adjust the critical properties for the heavier hydrocarbon fractions to achieve retrograde dew point pressure matching. For that, the critical temperatures, pressures and acentric factors were decreased by $60 \%$. The resulting dew point pressure was 5619 psia with 0.87 percent comparing with the reported pressure of 
5668 psia. The 4-Coeffcient methodology compositions and results are summarized in Table 22 and presented in Figure 18.

Table 18: Comparisons the Compositional Analysis for Rapid River 35 Field.

\begin{tabular}{|c|c|c|c|c|}
\hline Constituents & Experimental & Initial Extend & \multicolumn{2}{|c|}{ 4-Coeffcient } \\
\hline & $n=16$ & $\mathbf{n}=\mathbf{3 0}$ & $\mathrm{n}=\mathbf{2 4}$ & $\mathbf{n}=\mathbf{1 5}$ \\
\hline S. G. & 0.773 & 0.778 & 0.774 & 0.772 \\
\hline D. P. Pressure & 3309 & 3647 & 3329 & 3310 \\
\hline \multicolumn{5}{|c|}{ THE 4 COEFFICIENTS } \\
\hline $\mathrm{n}=7$ & & 15.5 & 10 & 10 \\
\hline $\mathrm{n}=8$ & & 15.5 & 11.75 & 12 \\
\hline $\mathrm{n}=9$ & & 17 & 15 & 15 \\
\hline $\mathrm{n}>10$ & & 17 & 27 & 19.25 \\
\hline $\mathbf{S C N}$ & \multicolumn{4}{|c|}{ MOLE FRACTIONS } \\
\hline 7 & 0.434 & 0.58501 & 0.42570 & 0.42570 \\
\hline 8 & 0.421 & 0.36425 & 0.41681 & 0.42755 \\
\hline 9 & 0.332 & 0.29873 & 0.40079 & 0.38721 \\
\hline 10 & 0.2354 & 0.15719 & 0.35916 & 0.26224 \\
\hline 11 & 0.1455 & 0.10792 & 0.05262 & 0.08064 \\
\hline 12 & 0.1007 & 0.07709 & 0.03643 & 0.05698 \\
\hline 13 & 0.0786 & 0.05597 & 0.02624 & 0.04125 \\
\hline 14 & 0.0475 & 0.04179 & 0.01964 & 0.03083 \\
\hline 15 & 0.0257 & 0.03189 & 0.01514 & 0.11810 \\
\hline 16 & 0.0101 & 0.02444 & 0.01189 & \\
\hline 17 & & 0.01856 & 0.00944 & \\
\hline 18 & & 0.01403 & 0.00757 & \\
\hline 19 & & 0.01048 & 0.00610 & \\
\hline 20 & & 0.00798 & 0.00500 & \\
\hline 21 & & 0.00643 & 0.00422 & \\
\hline 22 & & 0.00484 & 0.00349 & \\
\hline 23 & & 0.00384 & 0.00296 & \\
\hline 24 & & 0.00308 & 0.02729 & \\
\hline 25 & & 0.00251 & & \\
\hline 26 & & 0.00205 & & \\
\hline 27 & & 0.00168 & & \\
\hline 28 & & 0.00140 & & \\
\hline 29 & & 0.00115 & & \\
\hline 30 & & 0.00821 & & \\
\hline
\end{tabular}


Table 19: Comparisons the Compositional Analysis for Cold Spring 12 Field.

\begin{tabular}{|c|c|c|c|c|}
\hline Constituents & Experimental & Initial Extend & \multicolumn{2}{|c|}{ 4-Coeffcient } \\
\hline & $n=16$ & $\mathbf{n}=\mathbf{3 0}$ & $\mathbf{n}=\mathbf{3 0}$ & $n=23$ \\
\hline S. G. & 0.773 & 0.774 & 0.773 & 0.773 \\
\hline D. P. Pressure & 3620 & 3649 & 3318 & 3620 \\
\hline \multicolumn{5}{|c|}{ THE 4 COEFFICIENTS } \\
\hline $\mathrm{n}=7$ & & 15.5 & 14.75 & 14.25 \\
\hline $\mathrm{n}=8$ & & 15.5 & 14 & 14 \\
\hline $\mathrm{n}=9$ & & 17 & 13.25 & 13.5 \\
\hline $\mathrm{n}>10$ & & 17 & 13 & 13 \\
\hline SCN & \multicolumn{4}{|c|}{ MOLE FRACTIONS } \\
\hline 7 & 0.66 & 0.98573 & 0.95411 & 0.93243 \\
\hline 8 & 0.58 & 0.58339 & 0.54034 & 0.56721 \\
\hline 9 & 0.48 & 0.45850 & 0.35869 & 0.37370 \\
\hline 10 & 0.35 & 0.23119 & 0.27829 & 0.25585 \\
\hline 11 & 0.2 & 0.15413 & 0.21119 & 0.21187 \\
\hline 12 & 0.15 & 0.10742 & 0.15085 & 0.15134 \\
\hline 13 & 0.12 & 0.07629 & 0.10670 & 0.10704 \\
\hline 14 & 0.09 & 0.05587 & 0.07661 & 0.07685 \\
\hline 15 & 0.07 & 0.04190 & 0.05533 & 0.05550 \\
\hline 16 & 0.13 & 0.03157 & 0.03856 & 0.03868 \\
\hline 17 & & 0.02357 & 0.02488 & 0.02496 \\
\hline 18 & & 0.01753 & 0.01493 & 0.01497 \\
\hline 19 & & 0.01288 & 0.00819 & 0.00821 \\
\hline 20 & & 0.00966 & 0.00460 & 0.00462 \\
\hline 21 & & 0.00771 & 0.00302 & 0.00303 \\
\hline 22 & & 0.00572 & 0.00146 & 0.00147 \\
\hline 23 & & 0.00449 & 0.00086 & 0.00226 \\
\hline 24 & & 0.00356 & 0.00052 & \\
\hline 25 & & 0.00289 & 0.00032 & \\
\hline 26 & & 0.00234 & 0.00020 & \\
\hline 27 & & 0.00190 & 0.00012 & \\
\hline 28 & & 0.00157 & 0.00008 & \\
\hline 29 & & 0.00129 & 0.00005 & \\
\hline 30 & & 0.00888 & 0.00011 & \\
\hline
\end{tabular}


Table 20: Comparisons the Compositional Analysis for Chester 15 Field.

\begin{tabular}{|c|c|c|c|c|}
\hline Constituents & Experimental & Initial Extend & \multicolumn{2}{|c|}{ 4-Coeffcient } \\
\hline & $n=16$ & $\mathbf{n}=\mathbf{3 0}$ & $\mathrm{n}=12$ & $\mathbf{n}=\mathbf{1 1}$ \\
\hline S. G. & 0.756 & 0.771 & 0.762 & 0.758 \\
\hline D. P. Pressure & 2668 & 3153 & 2810 & 2709 \\
\hline \multicolumn{5}{|c|}{ THE 4 COEFFICIENTS } \\
\hline $\mathrm{n}=7$ & & 15.5 & 14 & 15.5 \\
\hline $\mathrm{n}=8$ & & 15.5 & 15 & 15.5 \\
\hline $\mathrm{n}=9$ & & 17 & 17 & 17 \\
\hline $\mathrm{n}>10$ & & 17 & 17 & 24 \\
\hline SCN & \multicolumn{4}{|c|}{ MOLE FRACTIONS } \\
\hline 7 & 0.4735 & 0.70753 & 0.66244 & 0.70753 \\
\hline 8 & 0.4775 & 0.40645 & 0.44437 & 0.40645 \\
\hline 9 & 0.3627 & 0.31170 & 0.33013 & 0.31170 \\
\hline 10 & 0.262 & 0.15339 & 0.15004 & 0.27228 \\
\hline 11 & 0.1597 & 0.10058 & 0.09838 & 0.24203 \\
\hline 12 & 0.0916 & 0.06915 & 0.25464 & \\
\hline 13 & 0.058 & 0.04851 & & \\
\hline 14 & 0.0315 & 0.03515 & & \\
\hline 15 & 0.0176 & 0.02611 & & \\
\hline 16 & 0.0059 & 0.01949 & & \\
\hline 17 & & 0.01442 & & \\
\hline 18 & & 0.01062 & & \\
\hline 19 & & 0.00774 & & \\
\hline 20 & & 0.00576 & & \\
\hline 21 & & 0.00457 & & \\
\hline 22 & & 0.00337 & & \\
\hline 23 & & 0.00263 & & \\
\hline 24 & & 0.00208 & & \\
\hline 25 & & 0.00168 & & \\
\hline 26 & & 0.00135 & & \\
\hline 27 & & 0.00109 & & \\
\hline 28 & & 0.00090 & & \\
\hline 29 & & 0.00074 & & \\
\hline 30 & & 0.00498 & & \\
\hline
\end{tabular}


Table 21: Comparisons the Compositional Analysis for Khuff 4 Field.

\begin{tabular}{|c|c|c|c|c|}
\hline Constituents & Experimental & Initial Extend & \multicolumn{2}{|c|}{ 4-Coeffcient } \\
\hline & $\mathbf{n}=\mathbf{2 0}$ & $\mathbf{n}=\mathbf{3 0}$ & $\mathbf{n}=\mathbf{3 0}$ & $+0.08 \% \mathrm{CP}$ \\
\hline S. G. & 0.76 & 0.786 & 0.786 & 0.786 \\
\hline D. P. Pressure & 5120 & 4260 & 4976 & 5112 \\
\hline \multicolumn{5}{|c|}{ THE 4 COEFFICIENTS } \\
\hline $\mathrm{n}=7$ & & 15.5 & 15.5 & 15.5 \\
\hline $\mathrm{n}=8$ & & 15.5 & 15.5 & 15.5 \\
\hline $\mathrm{n}=9$ & & 17 & 15 & 15 \\
\hline$n>10$ & & 17 & 15 & 15 \\
\hline SCN & \multicolumn{4}{|c|}{ MOLE FRACTIONS } \\
\hline 7 & 0.47 & 0.59066 & 0.60481 & 0.60481 \\
\hline 8 & 0.51 & 0.39915 & 0.40185 & 0.40185 \\
\hline 9 & 0.35 & 0.38904 & 0.26857 & 0.26857 \\
\hline 10 & 0.25 & 0.18848 & 0.21301 & 0.21301 \\
\hline 11 & 0.16 & 0.13399 & 0.15607 & 0.15607 \\
\hline 12 & 0.11 & 0.09864 & 0.11742 & 0.11742 \\
\hline 13 & 0.09 & 0.07371 & 0.08878 & 0.08878 \\
\hline 14 & 0.06 & 0.05649 & 0.06848 & 0.06848 \\
\hline 15 & 0.04 & 0.04417 & 0.05364 & 0.05364 \\
\hline 16 & 0.03 & 0.03470 & 0.04183 & 0.04183 \\
\hline 17 & 0.02 & 0.02708 & 0.03197 & 0.03197 \\
\hline 18 & 0.02 & 0.02107 & 0.02405 & 0.02405 \\
\hline 19 & 0.01 & 0.01623 & 0.01764 & 0.01764 \\
\hline 20 & 0.03 & 0.01269 & 0.01315 & 0.01315 \\
\hline 21 & & 0.01044 & 0.01050 & 0.01050 \\
\hline 22 & & 0.00809 & 0.00758 & 0.00758 \\
\hline 23 & & 0.00656 & 0.00585 & 0.00585 \\
\hline 24 & & 0.00536 & 0.00456 & 0.00456 \\
\hline 25 & & 0.00446 & 0.00363 & 0.00363 \\
\hline 26 & & 0.00371 & 0.00288 & 0.00288 \\
\hline 27 & & 0.00309 & 0.00227 & 0.00227 \\
\hline 28 & & 0.00261 & 0.00184 & 0.00184 \\
\hline 29 & & 0.00219 & 0.00146 & 0.00146 \\
\hline 30 & & 0.01737 & 0.00816 & 0.00816 \\
\hline
\end{tabular}


Table 22: Comparisons the Compositional Analysis for Dakhni Field.

\begin{tabular}{|c|c|c|c|c|}
\hline Constituents & Experimental & Initial Extend & \multicolumn{2}{|c|}{ 4-Coeffcient } \\
\hline & $\mathrm{n}=\mathbf{2 0}$ & $\mathbf{n}=\mathbf{3 0}$ & $n=25$ & $-0.60 \% \mathrm{CP}$ \\
\hline S. G. & 0.796 & 0.787 & 0.784 & 0.784 \\
\hline D. P. Pressure & 5668 & 5342 & 5430 & 5619 \\
\hline \multicolumn{5}{|c|}{ THE 4 COEFFICIENTS } \\
\hline $\mathrm{n}=7$ & & 15.5 & 13.5 & 13.5 \\
\hline $\mathrm{n}=8$ & & 15.5 & 15.5 & 15.5 \\
\hline $\mathrm{n}=9$ & & 17 & 18 & 18 \\
\hline $\mathrm{n}>10$ & & 17 & 21 & 21 \\
\hline SCN & \multicolumn{4}{|c|}{ MOLE FRACTIONS } \\
\hline 7 & 0.27 & 0.35854 & 0.32380 & 0.32380 \\
\hline 8 & 0.34 & 0.24041 & 0.28144 & 0.28144 \\
\hline 9 & 0.24 & 0.21021 & 0.22926 & 0.22926 \\
\hline 10 & 0.14 & 0.11802 & 0.16107 & 0.16107 \\
\hline 11 & 0.31 & 0.08484 & 0.06751 & 0.06751 \\
\hline 12 & & 0.06301 & 0.04892 & 0.04892 \\
\hline 13 & & 0.04739 & 0.03632 & 0.03632 \\
\hline 14 & & 0.03650 & 0.02777 & 0.02777 \\
\hline 15 & & 0.02865 & 0.02174 & 0.02174 \\
\hline 16 & & 0.02256 & 0.01721 & 0.01721 \\
\hline 17 & & 0.01762 & 0.01365 & 0.01365 \\
\hline 18 & & 0.01369 & 0.01088 & 0.01088 \\
\hline 19 & & 0.01051 & 0.00865 & 0.00865 \\
\hline 20 & & 0.00819 & 0.00698 & 0.00698 \\
\hline 21 & & 0.00673 & 0.00585 & 0.00585 \\
\hline 22 & & 0.00518 & 0.00474 & 0.00474 \\
\hline 23 & & 0.00418 & 0.00395 & 0.00395 \\
\hline 24 & & 0.00340 & 0.00333 & 0.00333 \\
\hline 25 & & 0.00282 & 0.02692 & 0.02692 \\
\hline 26 & & 0.00233 & & \\
\hline 27 & & 0.00193 & & \\
\hline 28 & & 0.00163 & & \\
\hline 29 & & 0.00136 & & \\
\hline 30 & & 0.01029 & & \\
\hline
\end{tabular}




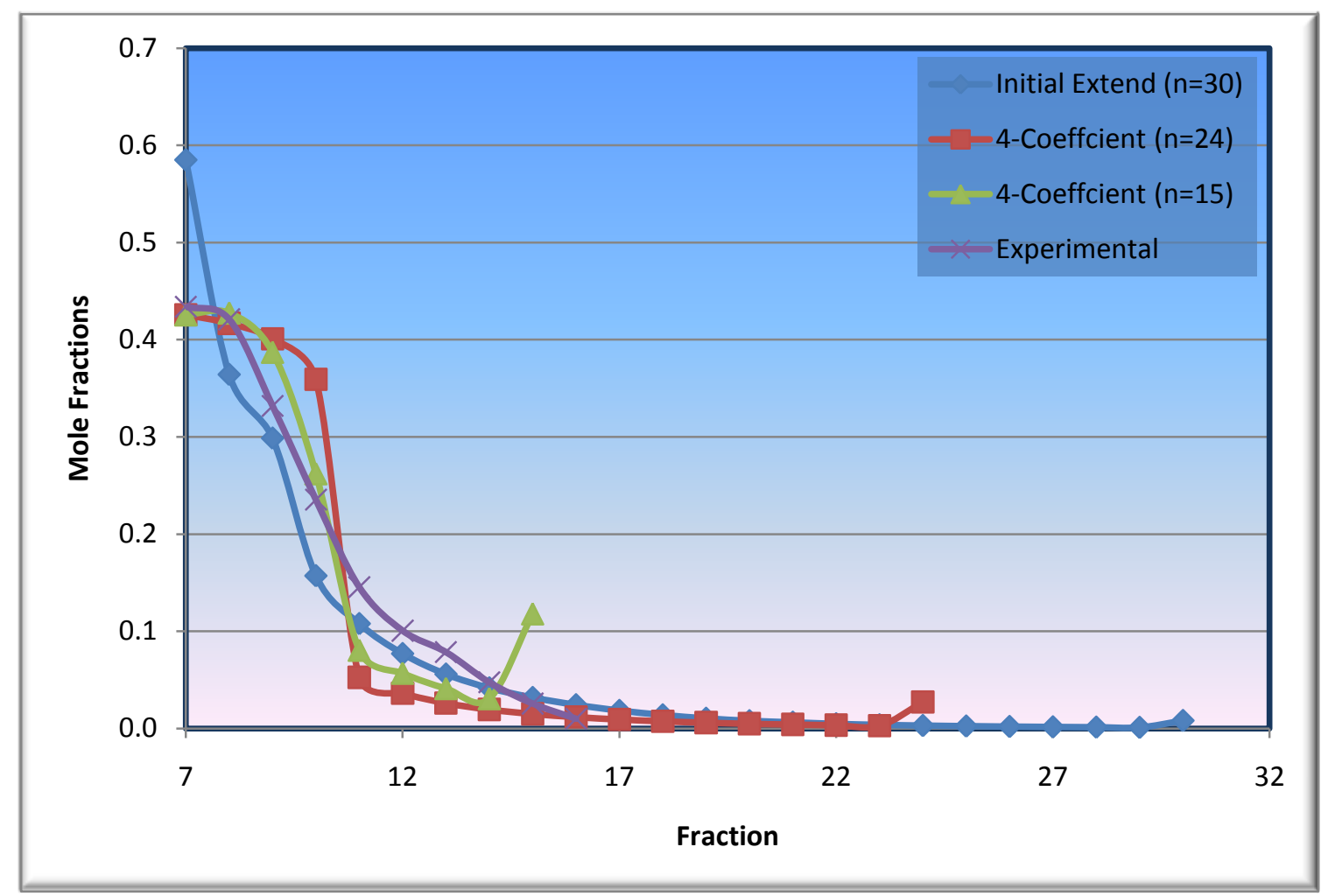

Figure 14: Comparisons the Compositional Analysis for Rapid River 35 Field.

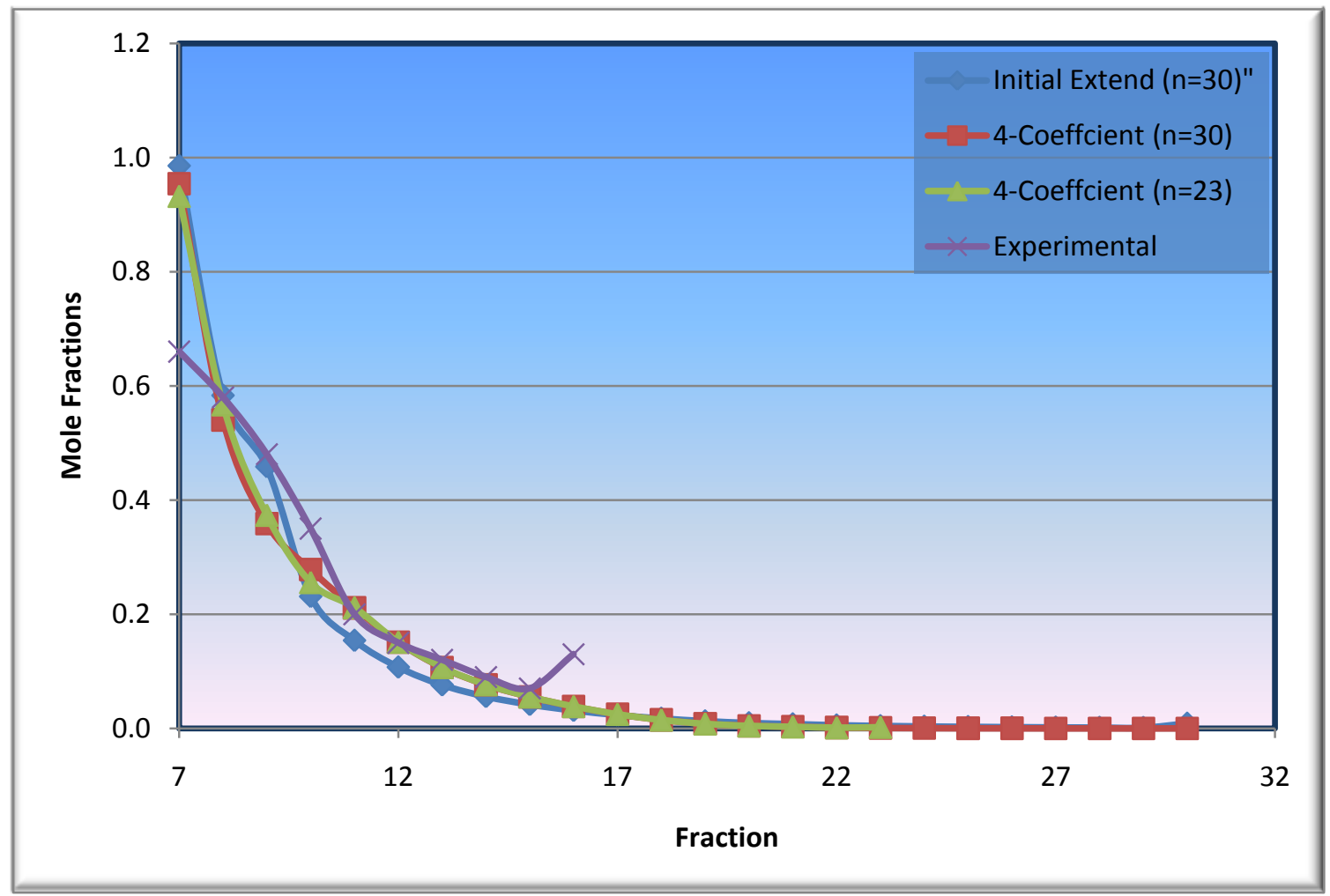

Figure 15: Comparisons the Compositional Analysis for Cold Spring 12 Field 


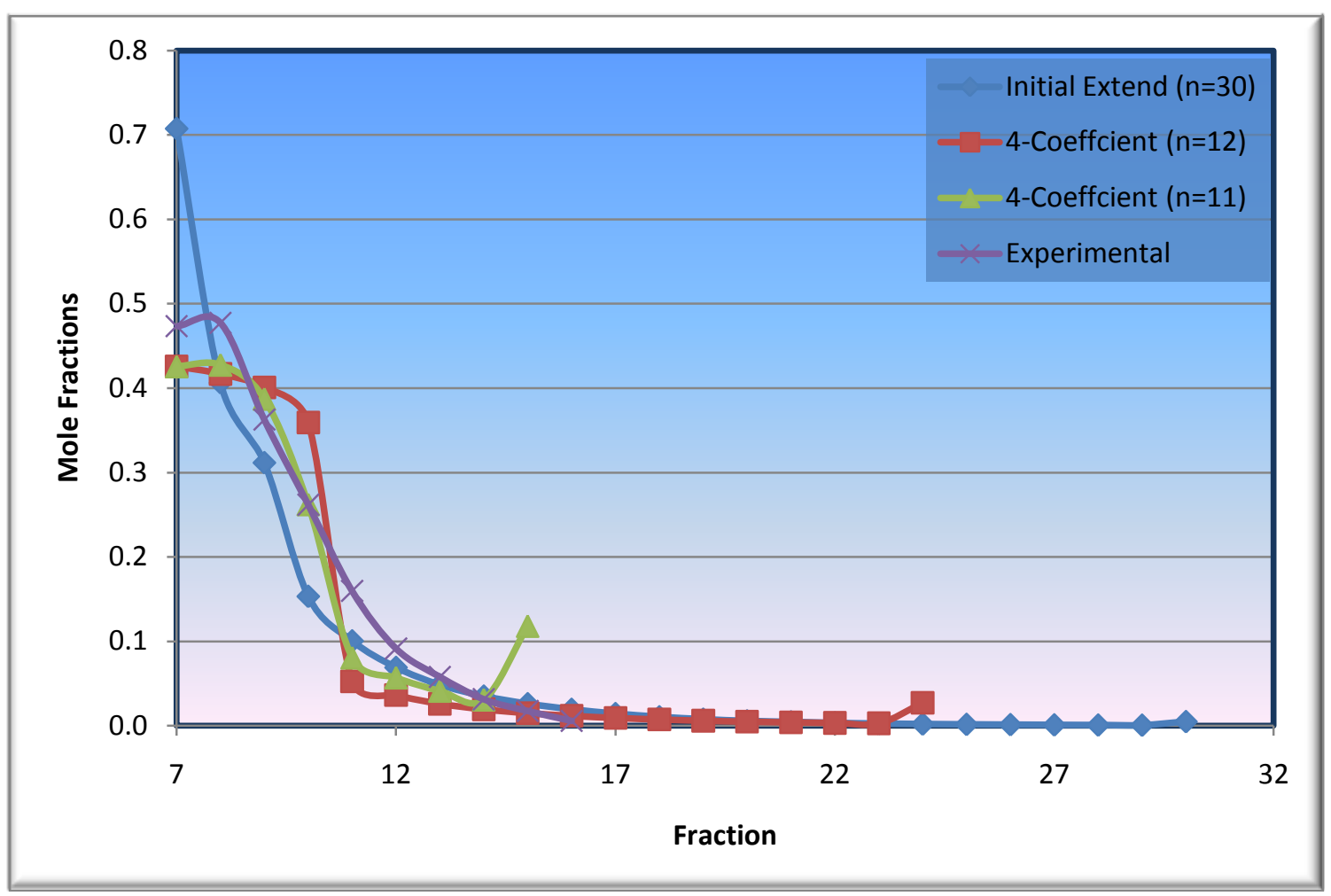

Figure 16: Comparisons the Compositional Analysis for Chester 15 Field

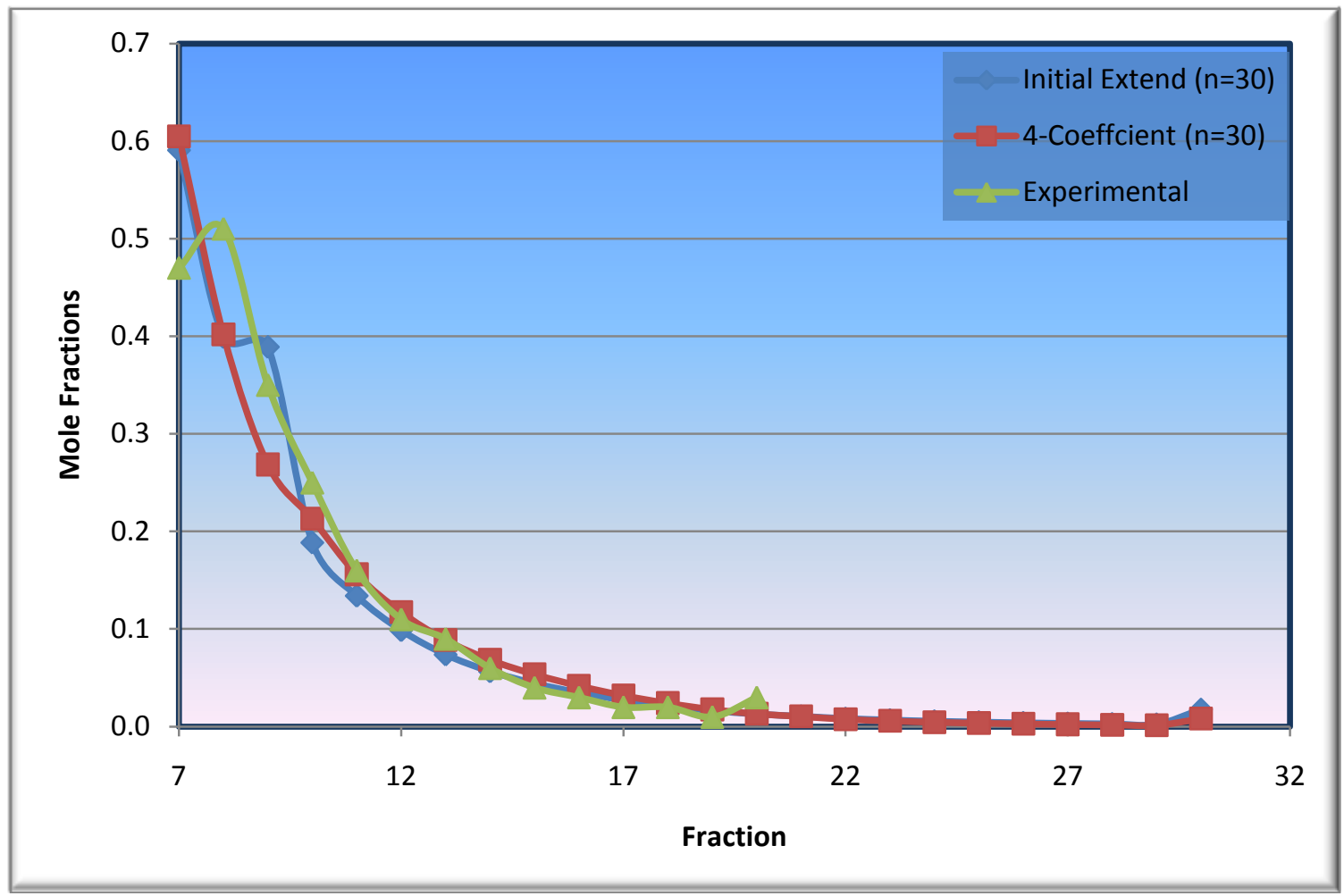

Figure 17: Comparisons the Compositional Analysis for Khuff 4 Field. 


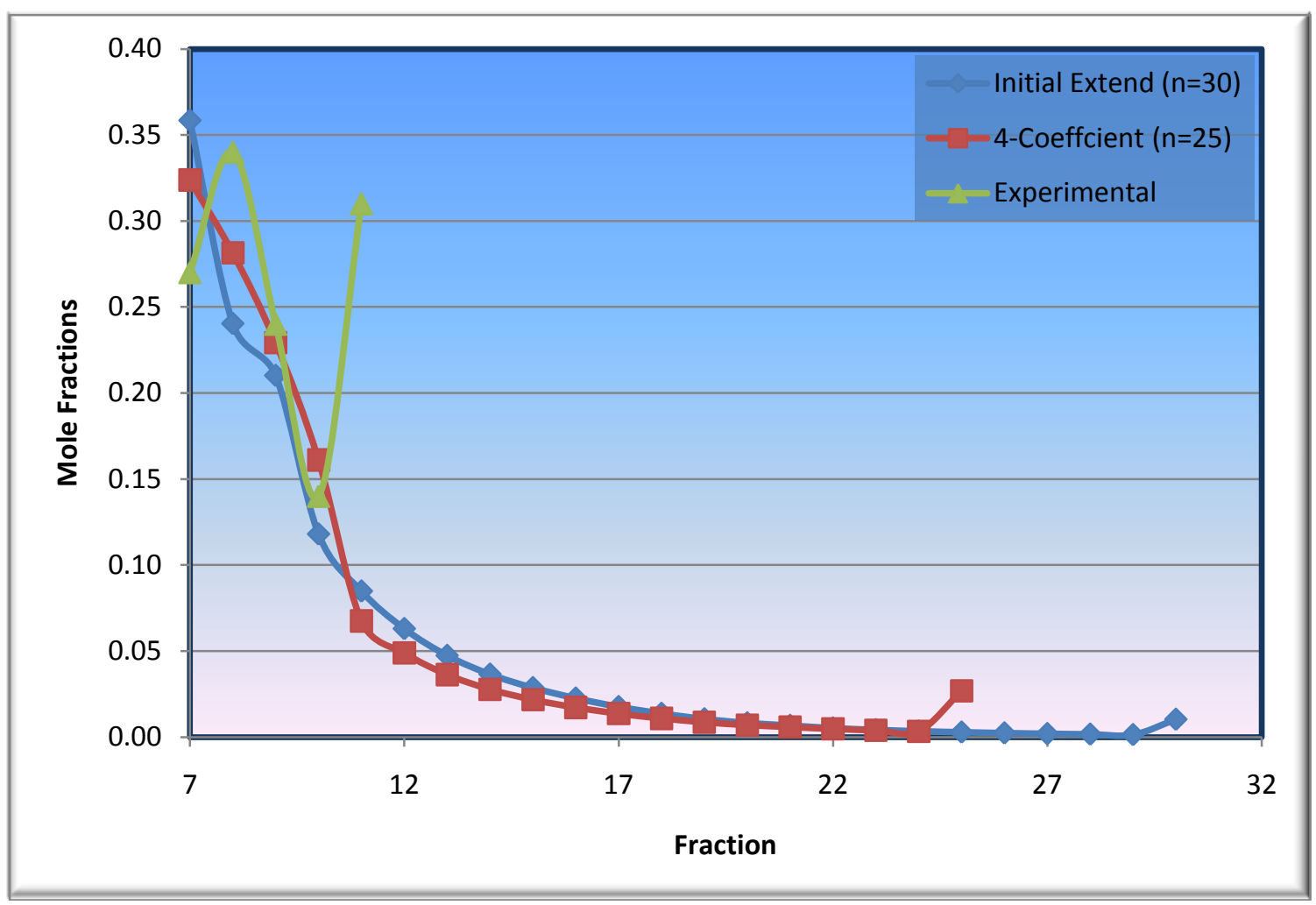

Figure 18: Comparisons the Compositional Analysis for Dakhni Field. 


\section{CHAPTER 5: CONCLUSIONS \& RECOMMENDATIONS}

The Katz's Splitting Scheme is easy to use but it gives results with much percentage of difference when matching the reporting lab results. The specific gravity and the retrograde dew point pressure differ from the lab results by non-excepted percentage, even.

Ahmed's Extend Method is good for splitting and the results are better than Katz method. The specific gravity is different in some cases by one or two percents whereas the retrograde dew point pressure had a range of differing from three to $5 \%$.

The Marching Technique with four specified slopes gave results close to Ahmed Extend Method. This method has deviation in the results about $3 \%$.

The Lohrenz \& Pederson methods need to have the mole fractions for more components heavier than hexane to determine the coefficients A\&B. for this reason; they are excluded because there are many samples don't have these heavier components mole fractions provided.

The 4-Coeffcient method gives better results comparing to the previous existing methods. Most of the results are within excepted range from the reported lab results. In some cases, it is needed to change the critical properties of the heavy fractions by some percent to get retrograde pressure closer. Each case or sample has best number of splitting components which may not applicable for other sample.

The proposed method is recommended to use as splitting scheme since it provides a reliable molar distribution for heavier hydrocarbon fraction. This methodology is validated through comparison with some published data. As a result, the 4-Coeffcient method provides a practical basis for studying the gas condensate reservoirs and their phase behaviors. 


\section{BIBLOGRAPHY}

Ahmed, T. H., Cady, G. V. \& Story, A. L. (1984). An accurate method for extending the analysis of $C_{7+}$. Paper SPE 12916. Rocky Mountain Regional Meeting. Casper, WY.

Ahmed, T. H., Cady G. V. \& Story, A. L. (1985). A generalized correlation for characterizing the hydrocarbon heavy fractions. Paper SPE 14266. Annual Technical Conference and Exhibition. Las Vegas, NV.

Ahmed, T. H. (2007). Equations of State and PVT Analysis: Applications for Improved Reservoir Modeling. Houston, TX: Gulf Publishing Company.

Almarry, J. A. (1983). Prediction of liquid recovery from a gas condensate reservoir ( doctoral dissertation, Petroleum Engineering Department, COMER, WVU 1983).

Aminian, K. (1989). Phase equilibrium and reservoir depletion calculations on PC using PR-EO: SPE Computer Applications. May-June.

Bradley, H. (1987). Petroleum engineering handbook. Richardson, TX: SPE.

Carsten, Slot-Petersen. (1989). A systematic and consistent approach to determine binary interaction coefficients for the peng-robinson equation of state", SPE. Dansk Olie- \& Gasproduktion A/S.

Core laboratory report of Dhakni gas condensate field for oil and gas development corporation. (1986). Pakistan.

Firoozabadi, A., Hekim, Y. \& Katz, D. (1978). Reservoir depletion calculation for gas condensate using extended analysis in PR-EOS. Canadian Journal of Chemical Engineering.

Hosein, R. (2003). Optimizing the number of components in tuning the Peng-Robinson Equation-of-State for Trinidad's gas condensates. Paper SPE 81113, Latin 
American and Caribbean Petroleum Engineering Conference. West Indies, Trinidad.

Hosein, R., McCain, W. D. \& Jagai, T. (2008). How to extend the heptanes plus fraction for gas condensate systems for use in compositional simulation. Paper SPE 113839. 2008 SPE Europec/EAGE Annual Conference and Exhibition. Rome, Italy, 9-12 June.

Ikoku, C. U. (1984). Natural gas reservoir engineering. John Wiley \& Sons.

Katz, D. (1983). Overview of phase behavior of oil and gas production. Journal of Petroleum Technology. pp. 1205-1214.

Katz D. L., Firoozabadi, A. (1978). Predicting phase behavior of condensate/crude oil systems using methane interaction coefficients. Journal of Petroleum Technology. pp. 6721.

Katz, D. L., Herzog, R. A., \& Hekim, Y. (1981). Predicting yield of revaporized condensate in gas storage. SPE 10166. Proceedings of Fall SPE Annual Technical Conference. San Antonio, TX.

Lohrenz, J., Bra, G. B, \& Clark, R. C. (1964). Calculating viscosities of reservoir fluids from their compositions. Journal of Petroleum Technology. pp. 1171-1176.

Malik, Q. M. (1990). A systematic methodology for determining gas-condensate extended compositional analysis (Master thesis, WVU, 1990).

Melkaveri, S. R. (2007). Compositional analysis and phase behavior prediction of heptanes plus components. Morgantown, WV: CEMR, WVU.

Peng, D. Y. \& Robinson, D. B. (1976). A new two constant equation of state. Industrial Engineering and Chemistry Fundamentals. 
Pedersen, K., Thomassen, P. \& Fredenslund, A. (1982). Phase equilibria and separation process. Report SEP 8207. Institute for Kemiteknik, Denmark. Tekniske Hojskole.

Redlich, O. \& Kwong, J. N. S. (1949). Thermodynamics of solutions v. an equation of state fugacities of gaseous solutions. Chem. Rev. 44. pp. 233.

Robinson, D. B., \& Peng, D. Y. (1978). The characterization of the heptanes and heavier fractions. (Report No. 28). Tulsa, OK: GPA.

Soave, G. (1972). Equilibrium constant from a modified Redlich-Kwong equation of state. Chem. Engr. Sci, 27. pp. 1197.

Van der Waals, J. D. (1873). On the Continuity of the Liquid and Gaseous State (doctoral dissertation). Universiteit Leiden. Leiden, Netherlands. 


\section{APPENDIX: GENERALIZED PHYSICAL PROPERTIES}

\begin{tabular}{|c|c|c|c|c|c|c|c|c|}
\hline Group & $\mathrm{Tb},{ }^{\circ} \mathrm{R}$ & SG & $\mathbf{K}$ & $\mathbf{M}$ & $\mathrm{Tc},{ }^{\circ} \mathrm{R}$ & Pc, psia & $\mathbf{w}$ & Vc, $\mathrm{ft}^{3} / \mathrm{lb}$ \\
\hline C6 & 607 & 0.69 & 12.27 & 84 & 923 & 483 & 0.250 & 0.06395 \\
\hline $\mathrm{C} 7$ & 685 & 0.727 & 11.96 & 96 & 985 & 453 & 0.280 & 0.06289 \\
\hline $\mathrm{C} 8$ & 702 & 0.749 & 11.87 & 107 & 1036 & 419 & 0.312 & 0.06264 \\
\hline C9 & 748 & 0.768 & 11.82 & 121 & 1085 & 383 & 0.348 & 0.06258 \\
\hline $\mathrm{C} 10$ & 791 & 0.782 & 11.83 & 134 & 1128 & 351 & 0.385 & 0.06273 \\
\hline C11 & 829 & 0.793 & 11.85 & 147 & 1166 & 325 & 0.419 & 0.06291 \\
\hline $\mathrm{C} 12$ & 867 & 0.804 & 11.86 & 161 & 1203 & 302 & 0.454 & 0.06306 \\
\hline C13 & 901 & 0.815 & 11.85 & 175 & 1236 & 286 & 0.484 & 0.06311 \\
\hline $\mathrm{C} 14$ & 936 & 0.826 & 11.84 & 190 & 1270 & 270 & 0.516 & 0.06316 \\
\hline $\mathrm{C} 15$ & 971 & 0.836 & 11.84 & 206 & 1304 & 255 & 0.550 & 0.06325 \\
\hline $\mathrm{C} 16$ & 1002 & 0.843 & 11.87 & 222 & 1332 & 241 & 0.582 & 0.06342 \\
\hline $\mathrm{C} 17$ & 1032 & 0.851 & 11.87 & 237 & 1360 & 230 & 0.613 & 0.0635 \\
\hline C18 & 1055 & 0.856 & 11.89 & 251 & 1380 & 222 & 0.638 & 0.06362 \\
\hline $\mathrm{C} 19$ & 1077 & 0.861 & 11.91 & 263 & 1400 & 214 & 0.662 & 0.06372 \\
\hline $\mathrm{C} 20$ & 1101 & 0.866 & 11.92 & 275 & 1421 & 207 & 0.690 & 0.06384 \\
\hline $\mathrm{C} 21$ & 1124 & 0.871 & 11.94 & 291 & 1442 & 200 & 0.717 & 0.06394 \\
\hline $\mathrm{C} 22$ & 1146 & 0.876 & 11.95 & 300 & 1461 & 193 & 0.743 & 0.06402 \\
\hline $\mathrm{C} 23$ & 1167 & 0.881 & 11.95 & 312 & 1480 & 188 & 0.768 & 0.06408 \\
\hline $\mathrm{C} 24$ & 1187 & 0.885 & 11.96 & 324 & 1497 & 182 & 0.793 & 0.06417 \\
\hline $\mathrm{C} 25$ & 1297 & 0.888 & 11.99 & 337 & 1515 & 177 & 0.819 & 0.06431 \\
\hline $\mathrm{C} 26$ & 1226 & 0.892 & 12.00 & 349 & 1531 & 173 & 0.844 & 0.06438 \\
\hline $\mathrm{C} 27$ & 1244 & 0.896 & 12.00 & 360 & 1547 & 169 & 0.868 & 0.06443 \\
\hline $\mathrm{C} 28$ & 1262 & 0.899 & 12.02 & 372 & 1562 & 165 & 0.894 & 0.06454 \\
\hline C29 & 1277 & 0.902 & 12.03 & 382 & 1574 & 161 & 0.915 & 0.06459 \\
\hline C30 & 1294 & 0.905 & 12.04 & 394 & 1589 & 158 & 0.941 & 0.06468 \\
\hline C31 & 1310 & 0.909 & 12.04 & 404 & 1603 & 143 & 0.897 & 0.06469 \\
\hline C32 & 1326 & 0.912 & 12.05 & 415 & 1616 & 138 & 0.909 & 0.06475 \\
\hline C33 & 1341 & 0.915 & 12.05 & 426 & 1629 & 134 & 0.921 & 0.0648 \\
\hline C34 & 1355 & 0.917 & 12.07 & 437 & 1640 & 130 & 0.932 & 0.06489 \\
\hline C35 & 1368 & 0.92 & 12.07 & 445 & 1651 & 127 & 0.942 & 0.0649 \\
\hline C36 & 1382 & 0.922 & 12.08 & 456 & 1662 & 124 & 0.954 & 0.06499 \\
\hline C37 & 1394 & 0.925 & 12.08 & 464 & 1673 & 121 & 0.964 & 0.06499 \\
\hline C38 & 1407 & 0.927 & 12.09 & 475 & 1683 & 118 & 0.975 & 0.06506 \\
\hline C39 & 1419 & 0.929 & 12.10 & 484 & 1693 & 115 & 0.985 & 0.06511 \\
\hline $\mathrm{C} 40$ & 1432 & 0.931 & 12.11 & 495 & 1703 & 112 & 0.997 & 0.06517 \\
\hline $\mathrm{C} 41$ & 1442 & 0.933 & 12.11 & 502 & 1712 & 110 & 1.006 & 0.0652 \\
\hline $\mathrm{C} 42$ & 1453 & 0.934 & 12.13 & 512 & 1720 & 108 & 1.016 & 0.06529 \\
\hline $\mathrm{C} 43$ & 1464 & 0.936 & 12.13 & 521 & 1729 & 105 & 1.026 & 0.06532 \\
\hline $\mathrm{C} 44$ & 1477 & 0.938 & 12.14 & 531 & 1739 & 103 & 1.038 & 0.06538 \\
\hline $\mathrm{C} 45$ & 1487 & 0.94 & 12.14 & 539 & 1747 & 101 & 1.048 & 0.0654 \\
\hline
\end{tabular}

